\title{
Local overexpression of interleukin-1 family, member 6 relates to the development of tubulointerstitial lesions
}

\author{
Osamu Ichii ${ }^{1}$, Saori Otsuka ${ }^{1}$, Nobuya Sasaki ${ }^{2}$, Akira Yabuki ${ }^{4}$, Hiroshi Ohta ${ }^{3}$, Mitsuyoshi Takiguchi ${ }^{3}$, \\ Yoshiharu Hashimoto ${ }^{1}$, Daiji Endoh ${ }^{5}$ and Yasuhiro Kon ${ }^{1}$
}

Identification of factors that exacerbate a disease is important for the development of biomarkers. In this study, we discovered ectopic overexpression of interleukin-1 family, member-6 (IL-1F6) in several murine renal diseases. IL-1F6 participates in cytokine/chemokine production in the epithelium. In PCR array analysis for inflammatory mediators, IIff6 showed the highest expression in the kidney of the B6.MRLC1 glomerulonephritis model. IL-1F6 was localized in the epithelium from the DCTs to CCDs, which showed tubular dilations or epithelial deciduations. Ultrastructual examination of the epithelial cells revealed that IL-1F6 was localized on the cytoplasmic ribosome, vesicles, and nucleus. In and around these tubules, we found infiltrations of CD3-positive T-cells and nestin- or $\alpha$-smooth-muscle actin-positive mesenchymal cells. Expression of the IL-1F6 protein and IIff6 mRNA in the kidney was increased by the development of TILs in the B6.MRLC1 model and in lupus (BXSB, NZB/WF1, and MRL/lpr), nephrotic syndrome (ICGN), and streptozotocin-induced diabetic models. IL-1F6 was also detected in the epithelia having squamous or deciduous contours in other organs such as the skin, esophagus, thymus, or uterus. In vitro analysis using $\mathrm{M}-1$ cells from the murine collecting duct revealed that II1f6 mRNA induction was related to the upregulation of IL-6, TGF- $\beta$ receptor-1, and mesenchymal markers and to the downregulation of epithelial markers and changes in the squamous cells of the epithelium. Interestingly, urine I/1f6 mRNA expression was detected earlier than renal dysfunctions in these mouse models. Ectopic overexpression of IL-1F6 in kidneys is associated with TILs and especially with cell infiltrations and changes in epithelial morphology. We propose that local overexpression of IL-1F6 is related to the development of TILs.

Laboratory Investigation (2010) 90, 459-475; doi:10.1038/labinvest.2009.148; published online 25 January 2010

KEYWORDS: biomarker; chronic kidney disease; collecting duct; distal convoluted tubule; interleukin-1 family member-6; luminal epithelial deciduation; tubulointerstitial lesion

It is predicted that the global population of patients with end-stage renal disease (ESRD) will increase from 4.3 (1990s) to 21.0 million (2010s). ${ }^{1}$ Chronic kidney disease (CKD) progresses to ESRD and can lead to development of risk conditions such as diabetes and hypertension (http:// www.kidney.org/kidneydisease/ckd/index.cfm). Chronic glomerulonephritis (CGN) and diabetic nephropathy (DN) are the major primary CKDs that necessitate dialysis. ${ }^{2}$

The most important strategy for control of CKD is development of a diagnostic method that can detect CKD at early stages. Recent studies have attempted to discover new biomarkers for renal diseases and elucidate their correlations with disease states. These studies reported that several factors that exacerbate renal disease, such as kidney injury molecule1 , monocyte chemoattractant protein-1, meprin, and osteopontin, could serve as biomarkers for injury of the proximal tubule (PT) epithelium, progression of DN, renal ischemiareperfusion injury, and focal segmental glomerulosclerosis, respectively. ${ }^{3-6}$

Typically, in order to discover new biomarkers, a comprehensive analysis of the genes that are upregulated in these diseases is essential. ${ }^{7}$ Microarray is a very useful analytical method; however, a large number of the relevant genes might be affected by the genetic background of the patients and/or

\footnotetext{
${ }^{1}$ Laboratory of Anatomy, Department of Biomedical Sciences, Graduate School of Veterinary Medicine, Hokkaido University, Hokkaido, Japan; ${ }^{2}$ Laboratory of Laboratory Animal Science and Medicine, Department of Disease Control, Graduate School of Veterinary Medicine, Hokkaido University, Hokkaido, Japan; ${ }^{3}$ Laboratory of Veterinary Internal Medicine, Department of Veterinary Clinical Sciences, Graduate School of Veterinary Medicine, Hokkaido University, Hokkaido, Japan; ${ }^{4}$ Laboratory of Clinical Pathology, Department of Veterinary Sciences, Kagoshima University, Kagoshima, Japan and ${ }^{5}$ Department of Veterinary Radiology, School of Veterinary Medicine, Rakuno Gakuen University, Hokkaido, Japan

Correspondence: Dr Y Kon, DVM, PhD, Laboratory of Anatomy, Department of Biomedical Sciences, Graduate School of Veterinary Medicine, Hokkaido University, Kita 18-Nishi 9, Kita-ku, Sapporo, Hokkaido 060-0818, Japan.
}

E-mail: y-kon@vetmed.hokudai.ac.jp

Received 15 July 2009; revised 9 October 2009; accepted 7 December 2009 
systemic diseases. Therefore, to establish new biomarkers, it is necessary to focus on factors that aggravate the disease. Kim et $a l^{8}$ reported that renal expression of inflammatory cytokines such as interleukin-1 (IL-1) was elevated in the early stages of murine immune-complex kidney disease. Furthermore, Teramoto et al $l^{9}$ showed that mRNA expression of chemokines and their receptors was upregulated in the glomerulus in the case of murine lupus nephritis (LN).

According to a report by Nangaku ${ }^{10}$, impairment of renal function correlates with tubulointerstitial lesions (TILs) rather than glomerular damage. Therefore, understanding the severity of TILs is important for prognosis. In a previous study, we developed the B6.MRLcl congenic mouse strain, which carried telomeric regions of chromosome- 1 from the $\mathrm{MRL} / \mathrm{MpJ}$ lupus-prone strain, as a CGN model. ${ }^{11-13}$ The B6.MRLc1 strain develops glomerular lesions from 6 months of age, and aged females eventually develop TILs; we therefore believe that chronic disease progression in this model more closely resembles CKD in humans than do other gene mutation mouse models with severe disease. Furthermore, since the B6.MRLcl strain has a clear genetic background and exhibits renal histopathological features, the B6.MRLc1 model is more suitable for the identification of factors that exacerbate renal diseases.

In the present study, by using aged B6.MRLc1 mice with CGN, we performed a comprehensive PCR array analysis that targeted various inflammatory mediators in an effort to identify factors that exacerbate renal diseases. The results of in vitro and in vivo assessment of several murine disease models indicated that IL-1 family, member-6 (IL-1F6) is closely associated with development of TILs.

\section{MATERIALS AND METHODS}

\section{Animals and Sample Preparations}

The investigators adhered to the Guide for the Care and Use of Animals of the School of Veterinary Medicine, Hokkaido University. The B6.MRLc1 CGN mouse model had already been generated in our previous studies. ${ }^{11-13}$ Female C57BL/6 mice (control); male BXSB, female NZB/W F1, and female $\mathrm{MRL} / \mathrm{lpr}$ mice (LN models); and male DBA/2 mice (streptozotocin (STZ)-induced diabetes model) were purchased from an animal-breeding company (Japan SLC, Nishi-Ku, Japan). The male ICGN nephrotic syndrome (NS) mouse strain was purchased from the Laboratory Animal Resource Bank, National Institute of Biomedical Innovation (Osaka, Japan). All animals were maintained under specific pathogen-free (SPF) conditions. The animals were divided into early- and late-stage groups according to disease severity: 4 and 5 months in male BXSB mice, 4 and 7 months in female $\mathrm{NZB} / \mathrm{W}$ F1 and MRL/lpr mice, 3 weeks and 3 months in male ICGN mice, and 4 and 6 months in female C57BL/6 mice. Under deep anesthesia (pentobarbital sodium; $50 \mathrm{mg} / \mathrm{kg}$ administered intraperitoneally), animals were killed by exsanguination from carotid arteries, and humoral and organ samples were collected. The organs were fixed by immersion or perfusion using 4\% paraformaldehyde (PFA) for histological or electron microscopic analysis. The remaining parts were stored fresh in RNAlater solution (Ambion, Austin, TX, USA) or at $-80^{\circ} \mathrm{C}$.

We referred to previous reports for the protocol for STZinduced diabetes. ${ }^{14,15}$ Briefly, diabetes was induced with intraperitoneal injections of STZ (Calbiochem, San Diego, CA, USA) dissolved in $0.05 \mathrm{M}$ sodium citrate buffer ( $\mathrm{pH} 4.5$ ). Mice received two rounds of injections of $40 \mathrm{mg} /(\mathrm{kg}$ day) STZ for 5 consecutive days, first at 8 weeks of age, and then, at 12 . The control animals received injections of citrate buffer. Fifteen-week-old mice were killed for analysis.

\section{Serological Analysis and Urinalysis}

In order to evaluate renal functions, serum blood urea nitrogen (BUN) and creatinine levels in all animals and urine glucose levels of diabetic mice were determined using BUN-test-Wako, Creatinine-test-Wako (Wako Pure Chemical Industries, Osaka, Japan), and Albusticks (Bayer Medical Corporation, Ebisu, Japan), respectively, according to the manufacturer's instructions. Urinary albumin was detected by the methods of combined sodium dodecyl sulfate-polyacrylamide gel electrophoresis (SDS-PAGE) and gel staining, as reported previously. ${ }^{11}$

\section{PCR Array Analysis}

To identify the factors that exacerbate the disease, PCR array analysis was performed and the relative expressions of 84 inflammatory cytokines, chemokines, and their receptors were examined. Total RNAs were purified from the stocked kidneys of 12-month-old female C57BL/6 and CGN mice using TRIzol reagent (Invitrogen, Carlsbad, CA, USA); the kidneys were stored in RNAlater solution. After purification of the total RNAs with an RNeasy Micro kit (Qiagen, Germantown, MD, USA), the RNAs were treated with Turbo DNase (Ambion) for DNA digestion and then purified again. One microgram of total RNA was synthesized to cDNAs using the $\mathrm{RT}^{2}$ PCR Array First Strand kit (SuperArray, Frederick, MD, USA). PCR array analysis was performed using $10 \mu \mathrm{l}$ of cDNA solution, Inflammatory Cytokines and Receptors $\mathrm{RT}^{2}$ Profiler PCR Arrays Type A version 3 (SuperArray), and the MX 3000 thermal cycler (Stratagene, La Jolla, CA, USA).

\section{Cell Culture}

Molecular and morphological changes in the epithelium after Illf6 induction were investigated using M-1 cells derived from murine renal collecting duct epithelium; these cells were purchased from Dainippon Sumitomo Pharma (Osaka, Japan). The cells were maintained in Ham's F-12 mediumDulbecco's modified Eagle's medium (DMEM/F12) (1:1) supplemented with $5 \%$ fetal bovine serum (FBS), penicillin and streptomycin $(100 \mathrm{U} / \mathrm{ml}), 2 \mathrm{mM}$ glutamine, and $5 \mu \mathrm{M}$ dexamethasone at $37^{\circ} \mathrm{C}$ in a humidified incubator with $5 \%$ $\mathrm{CO}_{2}$ up to $80 \%$ confluence in six-well dishes (BD Falcon, 
Franklin Lakes, NJ, USA). After 12 -h stimulation at $37^{\circ} \mathrm{C}$ by serum or urine $(10-100 \mu \mathrm{l})$ from $\mathrm{C} 57 \mathrm{BL} / 6$ and $\mathrm{MRL} / \mathrm{lpr}$ mice or spleen cells $\left(8 \times 10^{3}\right.$ to $4 \times 10^{4}$ cells $)$ from C57BL/6 mice, cultured cells were collected using $0.25 \%$ trypsin/ethylenediaminetetraacetic acid (EDTA) for molecular biological analysis. For morphological analysis, parts of cells were cultured on solid collagen gel (Nitta Gelatin, Toronto, ONT, Canada), stimulated by the same conditions with palate cultures, and fixed with 4\% PFA.

\section{Reverse Transcription and Real-Time PCR}

To examine mRNA expressions, total RNAs from stocked organs were purified using TRIzol reagent (Invitrogen) and the SV Total RNA Isolation System for cultured cells (Promega, Madison, WI, USA). DNase-treated total RNAs were synthesized to cDNAs and PCR for amplification and quantitative real-time PCR analysis were performed as described previously. ${ }^{12,13}$ Quantitative data were normalized to the expression of housekeeping Actb. Details of the specific primers used for each gene are provided in Table 1.

\section{Immunoblotting}

Stored kidneys were homogenized in modified RIPA lysis buffer ( $50 \mathrm{mM}$ Tris- $\mathrm{HCl}$ (pH 7.4), $150 \mathrm{mM} \mathrm{NaCl}, 1 \mathrm{mM}$ EDTA, $1 \%$ Triton X-100, $0.1 \%$ SDS, $1 \%$ sodium deoxycholate, $1 \mathrm{mM}$ PMSF, and $10 \mu \mathrm{l}$ protease inhibitor cocktail; Sigma, St Louis, MO, USA). Soluble protein was extracted by centrifugation at $10000 \mathrm{~g}$ for $10 \mathrm{~min}$ at $4^{\circ} \mathrm{C}$. Four-fold concentrated SDS-sample buffer $(200 \mathrm{mM}$ Tris- $\mathrm{HCl}$ (pH 6.8 ), $40 \%$ glycerol, $8 \%$ SDS, $0.04 \%$ bromophenol blue, and $24 \%$ 2-mercaptoethanol) was added to the extracted solutions and heated at $100^{\circ} \mathrm{C}$ for $3 \mathrm{~min}$. Electrophoresis was performed using $12.5 \%$ polyacrylamide gel (e-PAGEL; ATTO, Tokyo, Japan) and the protein was transferred to a polyvinylidene fluoride (PVDF) membrane (ATTO) by using a current density of $20 \mathrm{~mA} / \mathrm{mm}^{2}$. Blocking was performed in a $1 \times$ Chemiblocker (Millipore, Billerica, MA, USA) at room temperature for $1 \mathrm{~h}$. Goat anti-mouse IL-1F6 antibody (R\&D Systems, Minneapolis, MN, USA) diluted to 1:1000 was used as the primary antibody and was incubated with the protein sample overnight at $4^{\circ} \mathrm{C}$. Then, the proteins were washed with TBS/0.1\% Tween-20 and reacted with horseradish peroxidase (HRP)-labeled donkey anti-goat IgG diluted to 1:20 000 (Santa Cruz Biotechnology, Santa Cruz, CA, USA) at room temperature for $1 \mathrm{~h}$. Immunoreaction detection was performed using Immobilon Western Detection Reagent (Millipore).

\section{Histological Analysis}

Paraffin-embedded sections $(2 \mu \mathrm{m})$ of kidneys and collagencultured cells were stained with periodic acid Schiff (PAS) or Masson's trichrome (MT). For indices of proteinuria, the total number of urinary casts per PAS-stained kidney section was determined. For indices of renal fibrosis, digital images of the kidney sections stained with MT were prepared, and the area showing blue staining per total area of interstitial regions was measured using Image J version 1.32j (National Institutes of Health, Bethesda, MD, USA).

\section{IHC Analysis}

Indirect methods were preformed as described previously. ${ }^{11-13}$ The primary antibodies used were goat anti-mouse IL-1F6 antibodies (R\&D Systems) at 1:400 dilution, rabbit antimouse CD3 antibodies (Dako, Glostrup, Denmark) at 1:200 dilution, rabbit anti-mouse nestin antibodies (Covance, Princeton, NJ, USA) at 1:4000 dilution, and rabbit anti-human $\alpha$-SMA antibodies (Thermo Scientific, Waltham, MA, USA) at 1:150 dilution. For antigen retrieval, sections were autoclaved in $10 \mathrm{mM}$ citrate buffer $(\mathrm{pH} 6.0)$ at $105^{\circ} \mathrm{C}$ for $15 \mathrm{~min}$ for IL-1F6, nestin, and $\alpha$-SMA; the sections were incubated with $0.1 \%$ pepsin $/ 0.2 \mathrm{M} \mathrm{HCl}$ at $37^{\circ} \mathrm{C}$ for $5 \mathrm{~min}$ for CD3.

\section{Whole-Mount IHC Analysis}

Whole-mount immunohistochemical (IHC) analysis was performed to determine the localization of the IL-1F6 protein in the nephrons and collecting ducts. Whole kidneys from CGN mice were fixed in 4\% PFA and digested by incubation with $0.1 \mathrm{mg} / \mathrm{ml}$ collagenase/phosphate-buffered saline (PBS) solution (Gibco) for $1 \mathrm{~h}$ at $37^{\circ} \mathrm{C}$; connective tissues were microdissected under a stereoscopic microscope. After incubation with $6 \% \mathrm{H}_{2} \mathrm{O}_{2}$ /methanol to eliminate internal peroxidases, the specimens were washed with $100 \%$ methanol and incubated in dimethyl sulfoxide/methanol (1:1) containing $2.5 \%$ Triton-X for $30 \mathrm{~min}$. The specimens were washed with TST (10 mM Tris- $\mathrm{HCl}(\mathrm{pH} 7.8), 150 \mathrm{mM} \mathrm{NaCl}$, $1 \%$ Triton-X) and blocked for $6 \mathrm{~h}$ at room temperature with $5 \%$ skim milk/TST. For dilution of both primary and secondary antibodies, the above blocking solutions were used. Goat anti-mouse IL-1F6 antibody (R\&D Systems) at 1:400 dilution was used as the primary antibody and applied to the specimens for 2 days at $4{ }^{\circ} \mathrm{C}$ with mild rotation. The specimens were then rinsed with TST for $8 \mathrm{~h}$ and reacted with 1:100 diluted HRP-labeled donkey anti-goat IgG (Santa Cruz Biotechnology) overnight at $4{ }^{\circ} \mathrm{C}$ with mild rotation. The specimens were again rinsed with TST for $8 \mathrm{~h}$ and incubated with $250 \mu \mathrm{g} / \mathrm{ml}$ diaminobenzidine (DAB) solution/TST for 30 min on ice; $0.003 \% \mathrm{H}_{2} \mathrm{O}_{2}$ was added for color development. The specimens were then washed with TST, post-fixed in $4 \%$ PFA for $20 \mathrm{~min}$, and observed under a stereoscopic microscope.

\section{Immunofluorescence Analysis}

After antigen retrieval with $10 \mathrm{mM}$ citrate buffer ( $\mathrm{pH}$ 6.0) and serum blocking, immunofluorescence was performed as described in a previous study. ${ }^{12-13}$ In the first reaction, goat anti-mouse IL-1F6 antibodies (R\&D Systems) at a dilution of 1:200 and tetramethylrhodamine isothiocyanate (TRITC)conjugated rabbit anti-goat IgG antibodies (Zymed, San Francisco, CA, USA) at a dilution of 1:100 were used. 
Table 1 Summary of gene-specific primer pairs

\begin{tabular}{|c|c|c|c|c|c|c|}
\hline Gene name & Symbol & Accession no. & Forward primer & Reverse primer & $\begin{array}{l}\text { Product } \\
\text { size (bp) }\end{array}$ & Application \\
\hline Actin, $\alpha 2$, smooth & Acta2 & NM_007392.2 & 5'-CAGCACCATGAAGATCAA & 5'-CGTTCACAGTTG & 201 & Real-time PCR \\
\hline muscle, aorta & & & GATC-3' & TGTGCTAGAG-3' & & \\
\hline \multirow[t]{2}{*}{ Actin, $\beta$} & Actb & NM_007393.3 & 5'-TGTTACCAACTGGGACGA & 5'-GGGGTGTTGAAGGTC & 165 & RT-PCR, Real-time \\
\hline & & & $\mathrm{CA}-3^{\prime}$ & TCAAA-3' & & PCR \\
\hline \multirow[t]{2}{*}{ Cadherin-1 } & Cdh1 & NM_009864.2 & 5'-ACGTCCATGTGTGT & 5'-AGGAGCAGCAGGATC & 139 & Real-time PCR \\
\hline & & & GACTGTG-3' & AGAATC-3' & & \\
\hline \multirow[t]{2}{*}{ Claudin-3 } & Cldn3 & NM_009902.3 & $5^{\prime}$-GCACCCACCAA & 5'-TCGTCTGTCACCATCT & 206 & Real-time PCR \\
\hline & & & GATCCTCTA-3' & GGAA-3' & & \\
\hline \multirow[t]{2}{*}{ Fibronectin-1 } & $F n 1$ & NM_010233.1 & 5'-TGACAACTGCCGTA & 5'-TCGTCTCTGTCAGCTT & 162 & Real-time PCR \\
\hline & & & GACCTG-3' & GCAC- $3^{\prime}$ & & \\
\hline \multirow{4}{*}{$\begin{array}{l}\text { Interleukin-1 family, } \\
\text { member-6 }\end{array}$} & $1 / 1 f 6$ & NM_019450.3 & 5'-GAGCAAA & 5'-ATCTTGAGAGAG & 408 & RT-PCR in organs \\
\hline & & & CAGTTCCAGTCAC-3' & TGCCACAG-3' & & or cells \\
\hline & & & 5'-CAGCATCACCTTCGCTTA & 5'-AGTGTCCAGAT & 143 & RT-PCR in urine, \\
\hline & & & GAC-3' & ATTGGCATGG-3' & & Real-time PCR \\
\hline \multirow[t]{2}{*}{ Interleukin-6 } & 116 & NM_031168.1 & 5'-AGCCAGAGTCCTTCAGA & 5'-GCCACTCCTTCTGTG & 140 & Real-time PCR \\
\hline & & & GAG-3' & ACTCC-3' & & \\
\hline \multirow[t]{2}{*}{ Keratin-8 } & Krt8 & NM_031170.2 & 5'-GGAGATGGC & 5'-TGTTCTGCATCCCAG & 200 & Real-time PCR \\
\hline & & & CATTAAGGATG-3' & ACTCC-3' & & \\
\hline Matrix metallopepti- & Mmp9 & NM_013599.2 & $5^{\prime}$-TGGGTGTACACAGGCAA & 5'-ACTCCTTATCCACGCG & 199 & Real-time PCR \\
\hline dase-9 & & & $\mathrm{GAC}-3^{\prime}$ & AATG-3' & & \\
\hline \multirow[t]{2}{*}{ Nestin } & Nes & NM_016701.3 & $5^{\prime}$-GCTGGAACAGA & 5'-CATCTTGAGGTGTGCC & 157 & Real-time PCR \\
\hline & & & GATTGGAAGG & AGTTG-3' & & \\
\hline \multirow[t]{2}{*}{ Occludin } & Ocln & NM_008756.2 & $5^{\prime}$-AGAGTA & 5'-CCACCATCCTCTTG & 128 & Real-time PCR \\
\hline & & & CATGGCTGCTGCTG-3' & ATGTGC-3' & & \\
\hline S100 calcium binding & $5100 a 4$ & NM_011311.1 & $5^{\prime}$-CAGGCAAAGAGGGTGA & 5'-GCAATGCAGGAC & 190 & Real-time PCR \\
\hline protein-A4 & & & CAAG-3' & AGGAAGAC- $3^{\prime}$ & & \\
\hline Transforming growth & Tgfb1 & NM_011577.1 & 5'-TTGCTCAGCTCCACAG & 5'-TGGTTGTAG & 183 & Real-time PCR \\
\hline factor, $\beta 1$ & & & AGA-3' & AGGGCAAGGAC-3' & & \\
\hline Transforming growth & Tgfbr 1 & NM_009370.2 & 5'-ACCTTCTGAT & 5'-TTCCTGTTGGCTGAG & 202 & Real-time PCR \\
\hline factor, $\beta$ receptor-1 & & & CCATCGGTTG-3' & TTGTG-3' & & \\
\hline
\end{tabular}


Table 1 Continued

\begin{tabular}{|c|c|c|c|c|c|c|}
\hline Gene name & Symbol & Accession no. & Forward primer & Reverse primer & $\begin{array}{l}\text { Product } \\
\text { size (bp) }\end{array}$ & Application \\
\hline Tight junction protein- & Tjp1 & NM_009386.1 & 5'-GCACCATGCCT & 5'-ACTCAACACACC & 122 & Real-time PCR \\
\hline 1 (zona occludens-1) & & & AAAGCTGTC-3' & ACCATTGC-3' & & \\
\hline Tight junction protein- & Tjp2 & NM_004817.2 & 5'-AATGCGAGGATCGAAA & 5'-TAGCTTCCTCTG & 158 & Real-time PCR \\
\hline 2 (zona occludens-2) & & & TAGC- $3^{\prime}$ & GTGTCCTG-3' & & \\
\hline \multirow[t]{2}{*}{ Vimentin } & Vim & NM_011701.4 & 5'-CAGGATTTCT & 5'-TCAAGGTCATCGTG & 171 & Real-time PCR \\
\hline & & & СTGCСTCTGC-3' & ATGCTG-3' & & \\
\hline
\end{tabular}

For double staining with hepatocyte nuclear factor- $4 \alpha$ $(\mathrm{Hnf} 4 \alpha)$ and nestin, rabbit anti-Hnf4 $\alpha$ antibodies (Cell Signaling Technology, Beverly, MA, USA), rabbit anti-nestin antibodies (Covance) at 1:100 dilution, and fluorescein sothiocyanate (FITC)-conjugated goat anti-rabbit IgG antibodies (Zymed) at 1:100 dilution were used, and the sections were examined under a fluorescence microscope (FSX100; Olympus).

\section{Immunoelectron Microscopy}

To investigate the cellular localization of this protein, the following post-embedding method was performed: kidney specimens were fixed in a solution of $4 \%$ PFA in $0.1 \mathrm{M}$ phosphate buffer $(\mathrm{PB})$ overnight at $4{ }^{\circ} \mathrm{C}$. The specimens were thoroughly washed in $\mathrm{PB}$ and then dehydrated by washing with a graded ethanol series; subsequently, the specimens were embedded in LR White resin (Ohken, Tokyo, Japan) and polymerized at $60^{\circ} \mathrm{C}$. Ultrathin sections were cut and mounted on nickel grids, and were subjected to the following treatments: (a) washing in PBS; (b) blocking with 1\% normal donkey serum/PBS for $60 \mathrm{~min}$; (c) incubation with a 1:100 dilution of goat anti-mouse IL-1F6 antibody (R\&D Systems) in blocking solution for $1 \mathrm{~h}$ at room temperature; (d) washing in PBS; (e) incubation with a 1:200 dilution of biotinylated donkey anti-goat IgG (Santa Cruz) for $30 \mathrm{~min}$; (f) washing in PBS; (g) incubation with a 1:100 dilution of gold (diameter, $10 \mathrm{~nm}$ )-conjugated streptavidin (British Biocell International, Cardiff, UK); (h) fixation in $1.25 \%$ glutaraldehyde/PBS for $5 \mathrm{~min}$; and (i) washing in distilled water. After air-drying, the sections were stained with lead citrate.

\section{Statistical Analysis}

Results were expressed as mean (standard error (s.e.)) and statistically analyzed using non-parametric Mann-Whitney $U$-test $(P<0.05)$. Correlation between two parameters was analyzed using Pearson's correlation test $(P<0.001)$.

\section{RESULTS}

\section{Selection of Factors that Exacerbate Renal Disease}

To evaluate candidate factors for renal diseases, PCR array analysis targeting 84 inflammatory cytokines, chemokines, and their receptors was performed using kidneys from aged female C57BL/6 control and CGN model mice (Table 2 and Supplementary File 1). In the CGN mouse, genes for the chemokine (C-X-C motif) ligand $(\mathrm{Cxcl})$, the chemokine (C-C motif) ligand $(\mathrm{Ccl})$, and their receptors ( $\mathrm{Ccr}$ and $\mathrm{Cxcr}$ ) were upregulated. We found that the Illf6 cytokine showed the highest expression level in CGN model mice (186-fold vs C57BL/6). Elevation in the expression level of the Illf6 cytokine was remarkable as compared with that of the other IL-1 family genes such as IL- $1 \alpha$, IL- $1 \beta$, IL-18, and IL-1F8 (Supplementary File).

\section{IL-1F6 and TILs in CGN Kidneys}

At 8 months, although the CGN model showed a clear glomerular membrane and proliferative lesions, the TILs were not severe (Figure 1a). At this stage, few IL-1F6-positive tubules were observed in the cortical renal tubules (Figure 1c). However, 12-month-old CGN model mice showed severe TILs such as tubular dilations, urinary casts, infiltrations of mononuclear cells, and interstitial fibrosis as well as a remarkable increase in the number of IL-1F6-positive tubules (Figure $1 \mathrm{~b}$ and $\mathrm{d}$ ).

Proteinuria and fibrosis scores were used as indices of TILs; they were histoplanimetrically calculated and compared to the number of IL-1F6-positive tubules in CGN models. Higher scores were associated with a significantly high number of IL-1F6-positive tubules (Figure 1e and f).

\section{IL-1F6 mRNA and Protein Expression in CGN Kidneys}

The female CGN model mice showed greater disease severity than male CGN mice. ${ }^{1-13}$ In accord with this tendency, female CGN mice showed higher Illf6 mRNA expression than male CGN mice and higher Illf6 mRNA expression than both male and female C57BL/6 mice at 12 months 
Table 2 Result of PCR array analysis

\begin{tabular}{|c|c|c|c|}
\hline Number & Accession no. & Symbol & $\begin{array}{c}\text { Female } \\
\text { B6.MRLc1 }(82-100) \\
\text { female C57BL6 }\end{array}$ \\
\hline 1 & NM_019450 & $1 / 1 f 6$ & 185.85 \\
\hline 2 & NM_009141 & $\mathrm{CxCl} 5$ & 74.44 \\
\hline 3 & NM_013654 & $\mathrm{CCl} 7$ & 29.41 \\
\hline 4 & NM_011333 & $\mathrm{Ccl} 2$ & 26.14 \\
\hline 5 & NM_021443 & $\mathrm{Ccl} 8$ & 20.79 \\
\hline 6 & NM_010548 & 1110 & 20.36 \\
\hline 7 & NM_016960 & $\mathrm{CCl} 20$ & 11.94 \\
\hline 8 & NM_011331 & $\mathrm{Ccl} 12$ & 9.70 \\
\hline 9 & NM_008176 & Cxcl1 & 9.11 \\
\hline 10 & NM_009914 & $\mathrm{Ccr} 3$ & 8.74 \\
\hline 11 & NM_008599 & $\mathrm{CxCl9}$ & 8.21 \\
\hline 12 & NM_013652 & $\mathrm{CCl} 4$ & 8.16 \\
\hline 13 & NM_013693 & Tnf & 7.82 \\
\hline 14 & NM_009917 & Ccr5 & 7.51 \\
\hline 15 & NM_008337 & Ifng & 7.35 \\
\hline 16 & NM_011337 & $\mathrm{Ccl} 3$ & 6.81 \\
\hline 17 & NM_009915 & $\mathrm{Ccr} 2$ & 6.36 \\
\hline 18 & NM_007719 & $\mathrm{Ccr} 7$ & 6.27 \\
\hline 19 & NM_013653 & $\mathrm{Ccl} 5$ & 5.81 \\
\hline 20 & NM_008401 & Itgam & 5.73 \\
\hline 21 & NM_011338 & $\mathrm{Ccl} 9$ & 5.46 \\
\hline 22 & NM_021274 & Cxcl10 & 5.20 \\
\hline 23 & NM_008348 & Il10ra & 4.72 \\
\hline 24 & NM_009778 & C3 & 4.16 \\
\hline 25 & NM_008518 & $L t b$ & 3.94 \\
\hline 26 & NM_009909 & $118 r b$ & 3.81 \\
\hline 27 & NM_008370 & $115 \mathrm{ra}$ & 3.78 \\
\hline 28 & NM_009910 & Cxcr3 & 3.75 \\
\hline 29 & NM_009139 & Ccl6 & 3.65 \\
\hline 30 & NM_011577 & $T g f b 1$ & 3.65 \\
\hline
\end{tabular}

CDNA samples are obtained from kidneys of 12-month-old mice. Values represent fold increase versus the control group.

(Figure 2a). Furthermore, relative Illf6 mRNA expression remarkably increased with age in the female CGN model (Figure $2 b)$. Size-specific bands of the IL-1F6 protein were obtained on immunoblot analysis of specimens from aged female CGN mice and MRL/lpr mice showing severe TIL (Figure 2c).

\section{IL-1F6 Protein Localization in CGN Kidneys}

Whole-mount IHC analysis of CGN kidneys showed IL-1F6reactions in the cortex (Figure 2a). IL-1F6-positive reactions were observed in epithelia from the distal convoluted tubules
(DCTs) to the cortical collecting ducts (CCDs) in single nephrons (Figure 3b-e).

Figure 3 shows the IHC localization of IL-1F6 in CGN kidneys. In DCTs, IL-1F6 was observed in the deciduous epithelia (Figure 4a), while in CCDs, IL-1F6 showed heterogeneous reaction patterns (Figure $4 \mathrm{~b}$ ). Dilated tubular epithelium facing urinary casts showed squamous change and strong IL-1F6-positive reactions (Figure 4c). Additionally, mononuclear cells were observed to infiltrate some IL-1F6-positive tubules (Figure 4d). IL-1F6-positive reactions were not merged with the Hnf4 $\alpha$-positive reactions, which was the marker for PTs (Figure 4e). Immunoelectron microscopic analysis of IL-1F6 revealed the presence of gold particles in both the cytoplasm and the nucleus of the renal tubular epithelium (Figure 4e). In the cytoplasm, the gold particles were mainly found to be located in the free ribosomes (Figure 4f). Furthermore, vesicles containing the gold particles were localized at the apex of epithelium and in the lumen of the tubules (Figure $4 \mathrm{~g}$ ).

\section{IL-1F6 mRNA and Protein Expression in Several Renal Disease Models}

We assessed the relative Illf6 mRNA expression and the number of IL-1F6-positive tubules in the kidneys of LN (BXSB, NZB/WF1, MRL/lpr) and NS (ICGN) models (Figure 5). In the early stages of the disease, mRNA expressions were significantly higher in BXSB mice than in C57BL/6 mice (Figure 5a). In the late stage of the disease, IL-1F6 mRNA expression was found to be higher in all the disease model mice than in the control C57BL/6 mice; in particular, MRL/lpr and NS models showed significant differences (Figure 5c). Further, the number of IL-1F6-positive tubules was significantly higher in all the disease model mice than in the C57BL/6 mice in both the early and late stages of the disease (Figure $5 \mathrm{~b}$ and $\mathrm{d}$ ).

In the STZ-induced diabetic model mice, blood and urine glucose increased with age to significantly higher values than those in the control mice (Figure 6a and b). In our previous study, we had confirmed that the distal tubules and collecting ducts were dilated in STZ-induced diabetic mice; however, glomerular damage was not noted in the renal cortex. ${ }^{15}$ In the STZ group, mice with mild histopathological changes in the kidney exhibited some IL-1F6-positive tubules (Figure 6c). Further, the number of dilated and IL-1F6positive tubules dramatically increased in mice with severe renal damage (Figure 6d). A significantly higher number of IL-1F6-positive tubules and more elevated Illf6 expression were observed in mice belonging to the STZ group than in those belonging to the control group (Figure 6e and f).

Relationships between IL-1F6 and other TIL markers were then assessed (Figure 7). CD3-positive cells and nestin or actin $\alpha$-2 smooth muscle aorta ( $\alpha$-SMA)-positive cells had infiltrated around IL-1F6-positive tubules (Figure 7b, d, f, and g). Notably, nestin and IL-1F6 proteins were colocalized in the same epithelium (Figure $7 \mathrm{~h}$ ). 

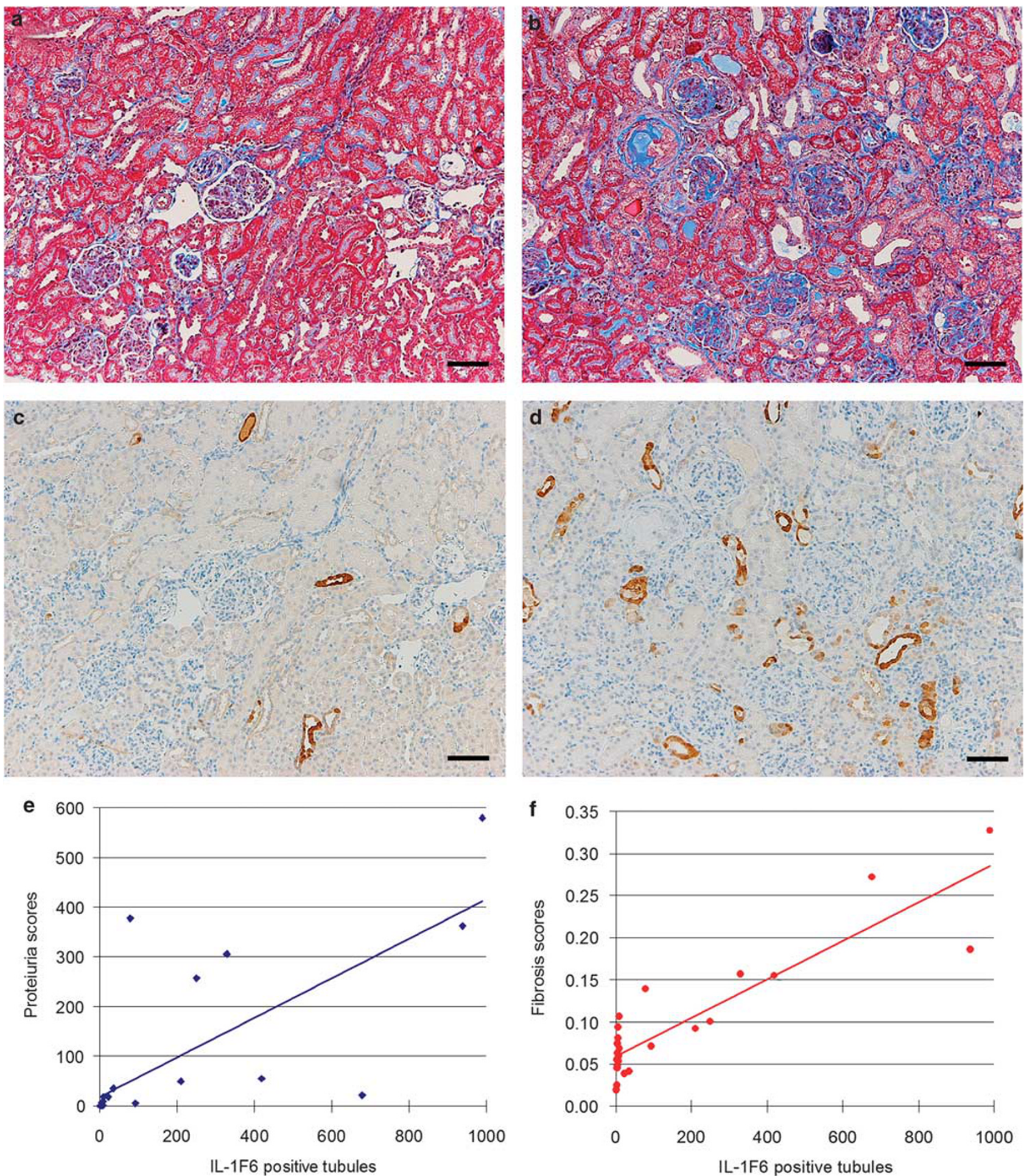

Figure 1 IL-1F6 and TILs in CGN mice. (a) Renal cortex of an 8-month-old female B6.MRLc1 mouse. The glomerulus showed proliferative and membranous lesions, but TILs were mild. MT stain. Bar $=50 \mu \mathrm{m}$. (b) Renal cortex of a 12-month-old female B6.MRLc1 mouse. Renal fibrosis and urinary casts can be clearly seen. MT stain. Bar $=50 \mu \mathrm{m}$. (c) IHC analysis of the IL-1F6 series in panel a. Small numbers of IL-1F6-positive tubules were observed. Bar $=50 \mu \mathrm{m}$. (d) IHC analysis of the IL-1F6 series in panel $\mathbf{b}$. A large number of IL-1F6-positive tubules were observed with development of TILs. In particular, elongated tubules containing urinary casts showed strong positive reactions. Bar $=50 \mu \mathrm{m}$. (e) Relationship between the number of IL-1F6-positive tubules ( $x$-axis) and indices for proteinuria ( $y$-axis) in a female B6.MRLc1 mouse. Pearson's correlation test $(P<0.001, r=0.738) ; n=26$. (f) Relationship between the number of IL-1F6positive tubules ( $x$-axis) and indices for fibrosis ( $y$-axis) in a female B6.MRLc1 mouse. Pearson's correlation test $(P<0.001, r=0.897) ; n=26$. 


\section{IL-1F6 mRNA and Protein Expression in Whole Organs}

IL-1F6 expressions in other organs were examined to predict the functions of IL-1F6. In both C57BL/6 and CGN models, Illf6 mRNA expression was detected mainly in the eye, thymus, trachea, esophagus, stomach, ovary, and uterus (Figure 8a). Expression in the skin, thymus, and uterus of the CGN mice was especially stronger than that in the C57BL/6 mice, and Illf6 expression in the kidney was detected only in the CGN model. IL-1F6 proteins were
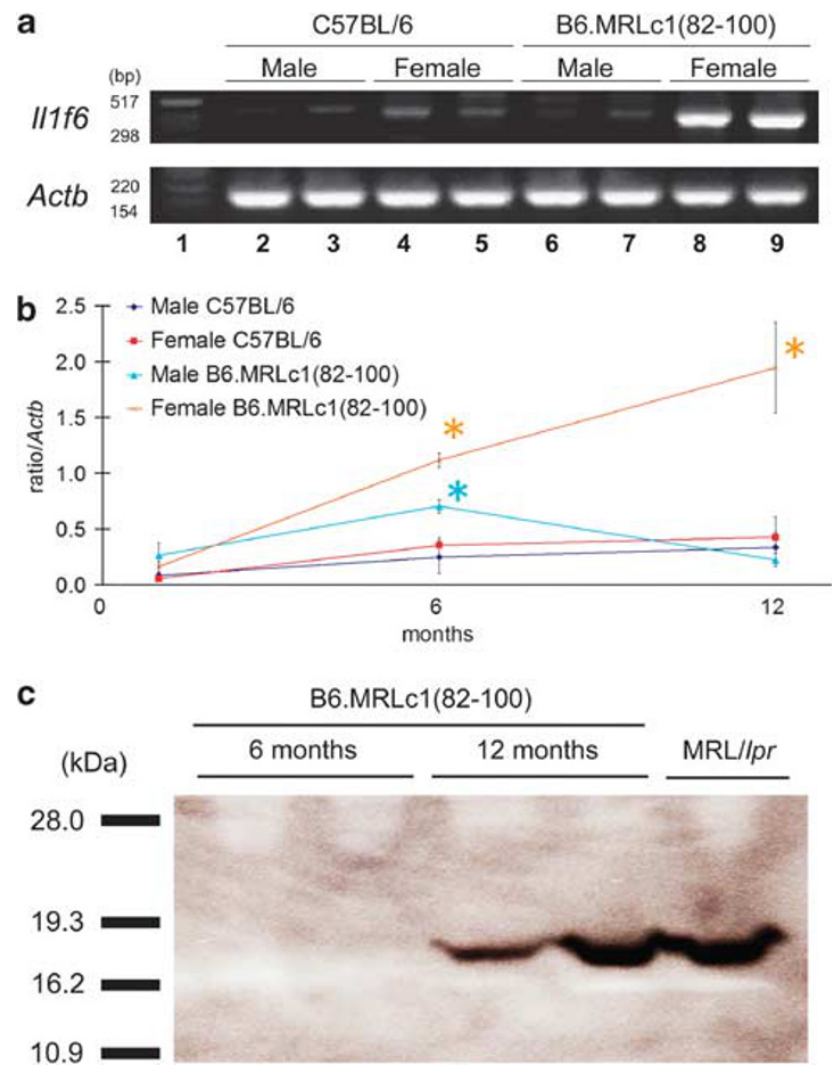

Figure 2 IIff6 mRNA and IL-1F6 protein expressions in the kidney of CGN mice. (a) Real-time PCR analysis of II1f6 (upper lane) and Actb (lower lane) mRNA expressions in the kidneys of 12-month-old C57BL/6 and B6.MRLc1 mice of both sexes. Size markers are represented on the left. (b) The time course of the levels of $111 \mathrm{f6}$ mRNA expressions in the kidneys of C57BL/6 and B6.MRLC1 mice of both sexes. Quantitative real-time PCR. Each value of II1f6 was normalized by that of Actb and represents the mean (s.e.); *: significantly different from age-matched, same-sex C57BL/6 mice (Mann-Whitney $U$-test, $P<0.05) ; n=3$ (each month). (c) Immunoblot analysis for IL-1F6 of the kidney of a B6.MRLc1 mouse. IL-1F6-specific bands (approximately $17 \mathrm{kDa}$ ) were observed in a 12-month-old female and 5-month-old MRL/Ipr mouse that showed severe TILs. Size markers are represented on the left. localized in the squamous or deciduous epithelium in these organs (Figure 8b-e).

\section{In vitro Induction of II1f6}

In order to determine its induction factor, Illf6 mRNA expression in an M-1 cell line derived from murine collecting duct epithelium was analyzed after stimulation with serum, urine, or spleen cells of mice. We found that Illf6 expression was only induced by co-culture with spleen cells, was dependent on the number of spleen cells, and reached a peak when stimulated with $1.6 \times 10^{4}$ cells (Figure $9 \mathrm{a}$ and $\mathrm{b}$ ).

\section{Molecular and Morphological Changes After In Vitro Induction of II1f6}

Figure 9c-e illustrates the mRNA expression of Illf6, IL-6 (Il6), transforming growth factor- $\beta$ (TGF- $\beta$ ) family members, and various epithelial and mesenchymal markers in M-1 cells stimulated by spleen cells. In addition to induction of Illf6 expression, we also observed upregulation of Il6, TGF- $\beta$ receptor-1 (Tgfbr1), actin $\alpha$-2 smooth-muscle aorta (Acta2, gene of $\alpha$-SMA), and matrix metallopeptidase- 9 (Mmp9), and downregulation of epithelial markers such as cadherin-1, tight junction protein-1, occludin, and claudin-3.

Figure of and g show the morphological changes in M-1 cells after stimulation with spleen cells embedded in collagen gel. Although M-1 cells normally show cuboidal epithelium and a regular paving morphology, the morphology of stimulated M-1 cells changed to the squamous type, and they tended to lose cellular adhesion (Figure 9g).

\section{Renal Functions and Urine IL-1F6 mRNA Expression}

Indices for renal functions, serum BUN, serum creatinine, and urinary albumin were measured in the C57BL/6, LN, NS, and STZ-induced diabetic models (Figure 10a-c). From these results, the LN and NS models clearly showed deterioration of renal function in the late stage of the disease. In the early stage, the NS model had severe albuminuria, and deterioration of renal function in the LN model was mild. There was no indication of renal function deterioration in the STZinduced diabetic model. Interestingly, urine Illf6 mRNA expression was detected in the LN and NS models as well as in the STZ-induced diabetic model from the early stage of the disease (Figure 10d).

\section{DISCUSSION}

\section{IL-1F6 Belongs to the IL-1 Family}

For comprehensive analysis, upregulation of chemokines and their receptors was elucidated in CGN kidneys. Interestingly,

Figure 3 Localization of IL-1F6 in whole kidneys of CGN mice. (a) Whole-mount IHC staining for IL-1F6 in the kidney of a 12-month-old female B6.MRLC1 mouse. Diffuse IL-1F6-positive reactions (dark brown) were observed in the renal cortex. The dotted line indicates the cut line. The direction of insertion is represented in the figure by the arrow. Bar $=250 \mu \mathrm{m}$. (b) Single dissected nephron comprising the region from the DCTs to the CCD observed on wholemount IHC staining. IL-F6-positive reactions were observed in the epithelium of the tubule and duct. Bar $=20 \mu$ m. (c) Schema for panel b. (d) Single dissected DCT after whole-mount IHC staining for IL-1F6. The epithelium shows a strong positive reaction. Bar $=20 \mu \mathrm{m}$. (d) Single dissected CCD after whole-mount IHC staining for IL-1F6. The epithelium shows a heterogeneous reaction. Bar $=20 \mu \mathrm{m}$. 

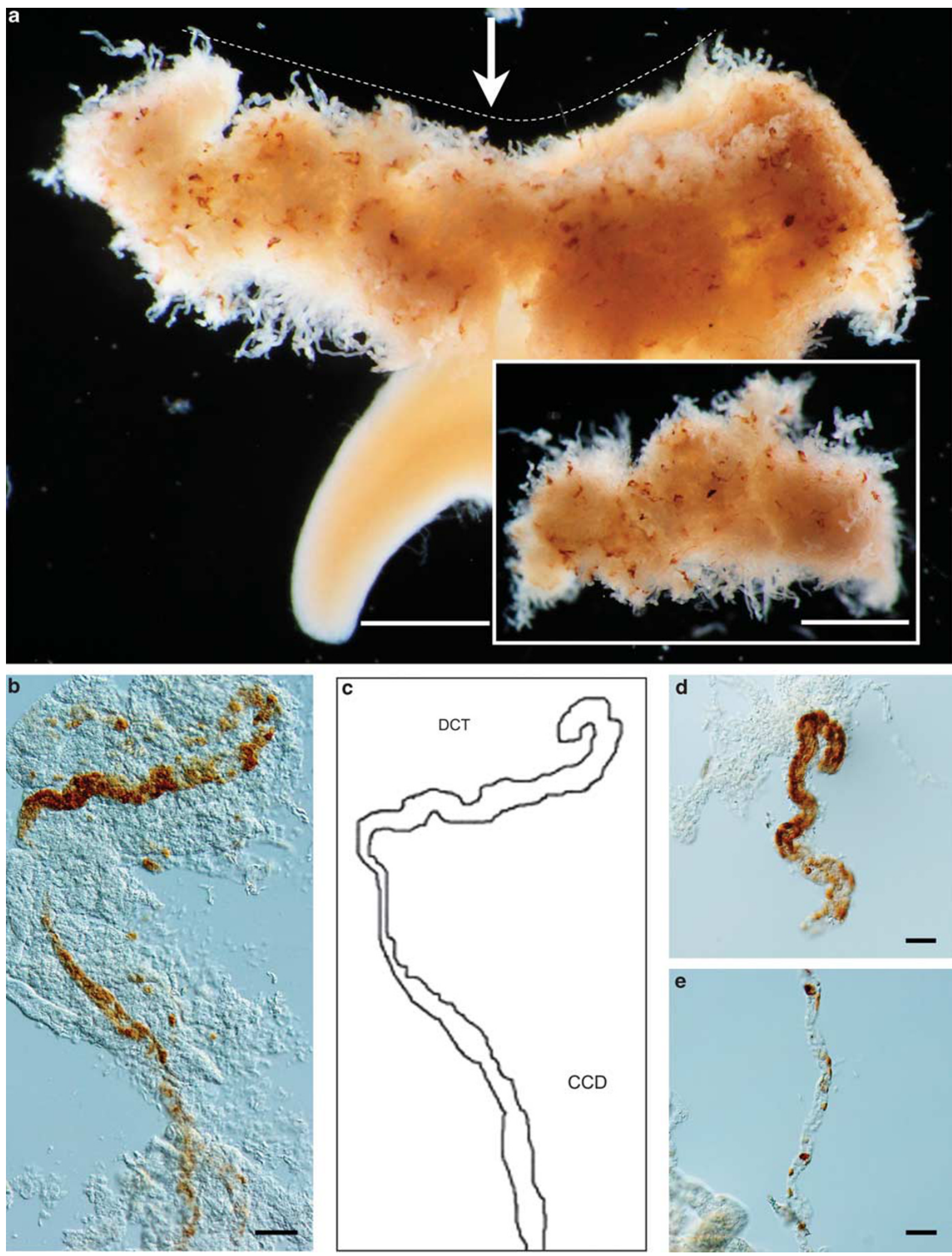
Illf6 but not a chemokine gene, showed the highest expression level. Il1f6 is also known as a member of the IL-1 (FIL1) gene family, and its product has been identified as a member
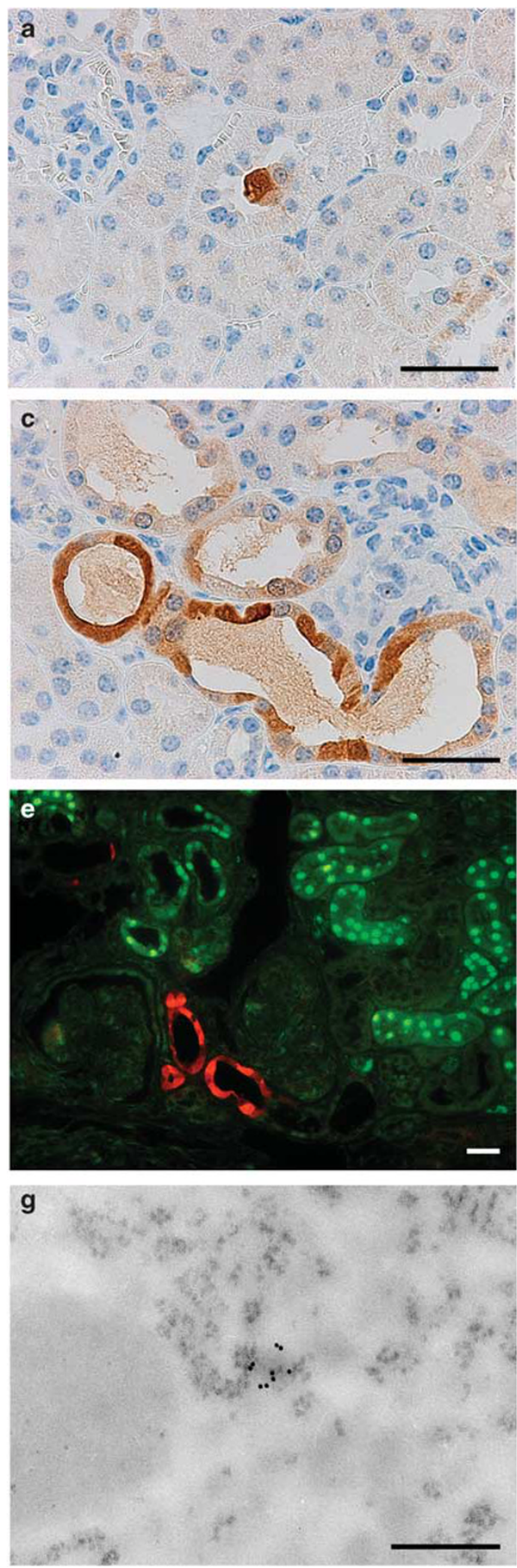

of the IL-1 cytokine family. ${ }^{16}$ The IL-1 family is composed of IL-1 $\alpha$, IL-1 $\beta$, IL-1Ra, IL-18, IL-1F5, IL-1F6, IL-1F7, IL-1F8, IL-1F9, IL-1F10, and IL-33. ${ }^{16}$ These members play important
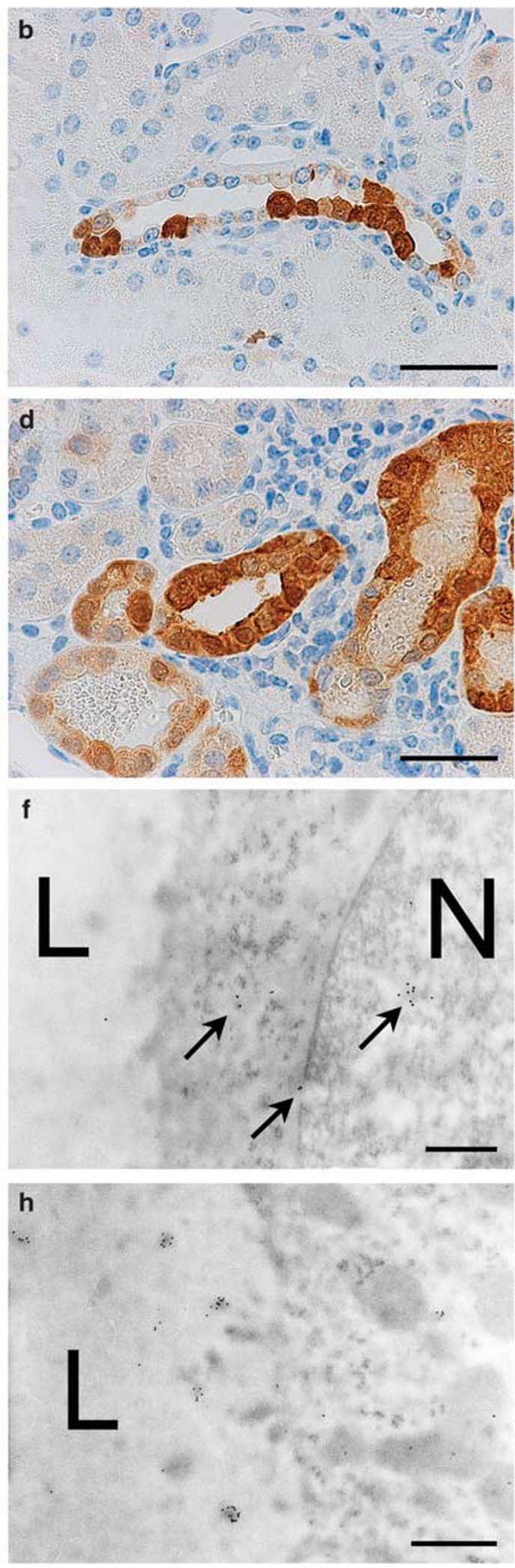
roles in the regulation of inflammation by mediating the expression of various cytokines, chemokines, nitric oxide synthase, and MMPs. ${ }^{16}$ Recent studies have reported that IL-1F5, IL-1F6, IL-1F7, IL-1F8, IL-1F9, and IL-1F10 (especially IL-1F6 and IL-1F8) accelerated inflammation by increasing the production of IL- 6 and IL- 8 in the epithelium. ${ }^{17}$

\section{Relationship between IL-1F6 and Development of TILs}

The relationship between the IL-1 family and disease has been generally reported in autoimmune diseases. ${ }^{16} \mathrm{IL}-1 \beta$ has been found to be produced by macrophages, T-cells, fibroblasts, and chondrocytes in articular cavities of rheumatic patients; it also participates in local inflammation and tissue remodeling via MMPs. ${ }^{16,18-22}$ Of the recently studied IL-1 members, IL-1F8 has been associated with the pathogenesis of rheumatism by increasing IL-6 and IL- 8 expression in synovial fibroblasts and chondrocytes. ${ }^{16,23}$ In renal diseases, it was reported that some IL-1 members aggravated renal fibrosis. ${ }^{24}$ A previous study suggested that IL- $1 \alpha$-positive interstitial cells correlated with the grade of TILs in IgA nephropathy. ${ }^{25}$ The correlation between IL- $1 \beta$ in interstitial cells and decline of renal function was reported in a group of primary glomerular diseases. ${ }^{26}$ However, PCR array analysis revealed that in CGN model mice, the mRNA expression of IL-1F6 was remarkably higher than that of the other IL-1 family proteins, including IL- $1 \alpha$, IL- $1 \beta$, IL-18, and IL-1F8 (Supplementary File). Furthermore, overexpression of IL-1F6 was observed in the kidneys of CGN-, LN-, NS-, and STZinduced diabetic mice, specifically in renal disease rather than in autoimmune disease. Thus, our study is the first to report a correlation between IL-1F6 ectopic overexpression and various renal diseases.

IL-1F6 was localized in the epithelium from the DCTs to CCDs in renal disease models, and T-cells were infiltrated around the IL-1F6-positive tubules. In vitro analysis clarified that Illf6 mRNA expression in epithelial cells could be induced by stimulation of the immune cells. Blumberg et al ${ }^{27}$ reported that transgenic mice overexpressing dermal IL-1F6
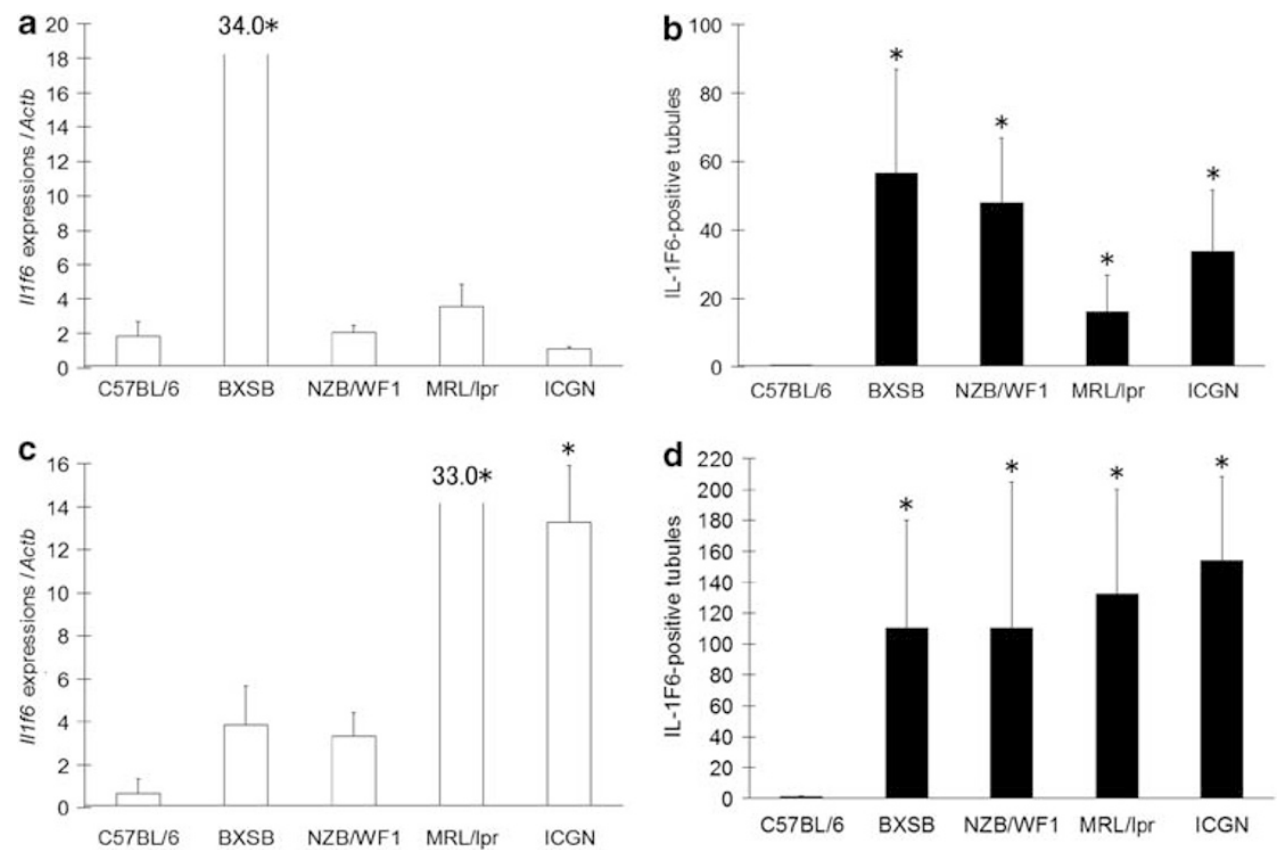

Figure 5 IL-1F6 protein and IIff6 mRNA expressions in the kidneys of various renal disease model mice. (a, c) The number of IL-1F6-positive tubules in the kidneys of C57BL/6 (control), lupus models (BXSB, NZB/WF1, MRL//pr), and NS model (ICGN) mice in the early (a) and late stages of the disease (c). (b, d) Levels of $I 11 f 6$ mRNA expressions in the kidneys of mice in the early (b) and late stages of the disease (d). Each value is expressed as mean (s.e.); *: significantly different from the C57BL/6 mice in each stage of the disease (Mann-Whitney U-test, $P<0.05$ ); $n=3$.

Figure 4 Localizations of IL-1F6 in the kidneys of CGN mice. (a) An IL-1F6-positive epithelial cell of the DCT tended to drop out to the tubular lumen in the kidney of a 12-month-old female B6.MRLc1 mouse. Bar $=20 \mu \mathrm{m}$. (b) In the IL-1F6-positive CCD, some positive epithelia showed strong reactions.

$\mathrm{Bar}=20 \mu \mathrm{m}$. (c, d) In some IL-1F6-positive tubules, the epithelium transformed to the squamous morphology accompanied by elongation of tubular lumina. Mononuclear cell infiltration was evident around these tubules. Bar $=20 \mu \mathrm{m}$. (e) IL-1F6-positive cells (TRITC, red) did not show colocalization with the Hnf4 $\alpha$ positive proximal tubular cells (FITC, green) (Figure 3e). Bar $=20 \mu \mathrm{m}$. (f-h) Post-embedding immunoelectron microscopic analysis revealed IL-1F6-positive signals (10-nm particles) in both the cytoplasm and nucleus (f, arrows). The gold particles were mainly localized on free ribosomes in the cytoplasm (g). In some renal tubules, gold particles were found to localize in vesicles at the apex of epithelium and tubular lumen (h). $N=$ nucleus, $L=$ lumen of renal tubule. $\mathrm{Bar}=200 \mathrm{~nm}$. 

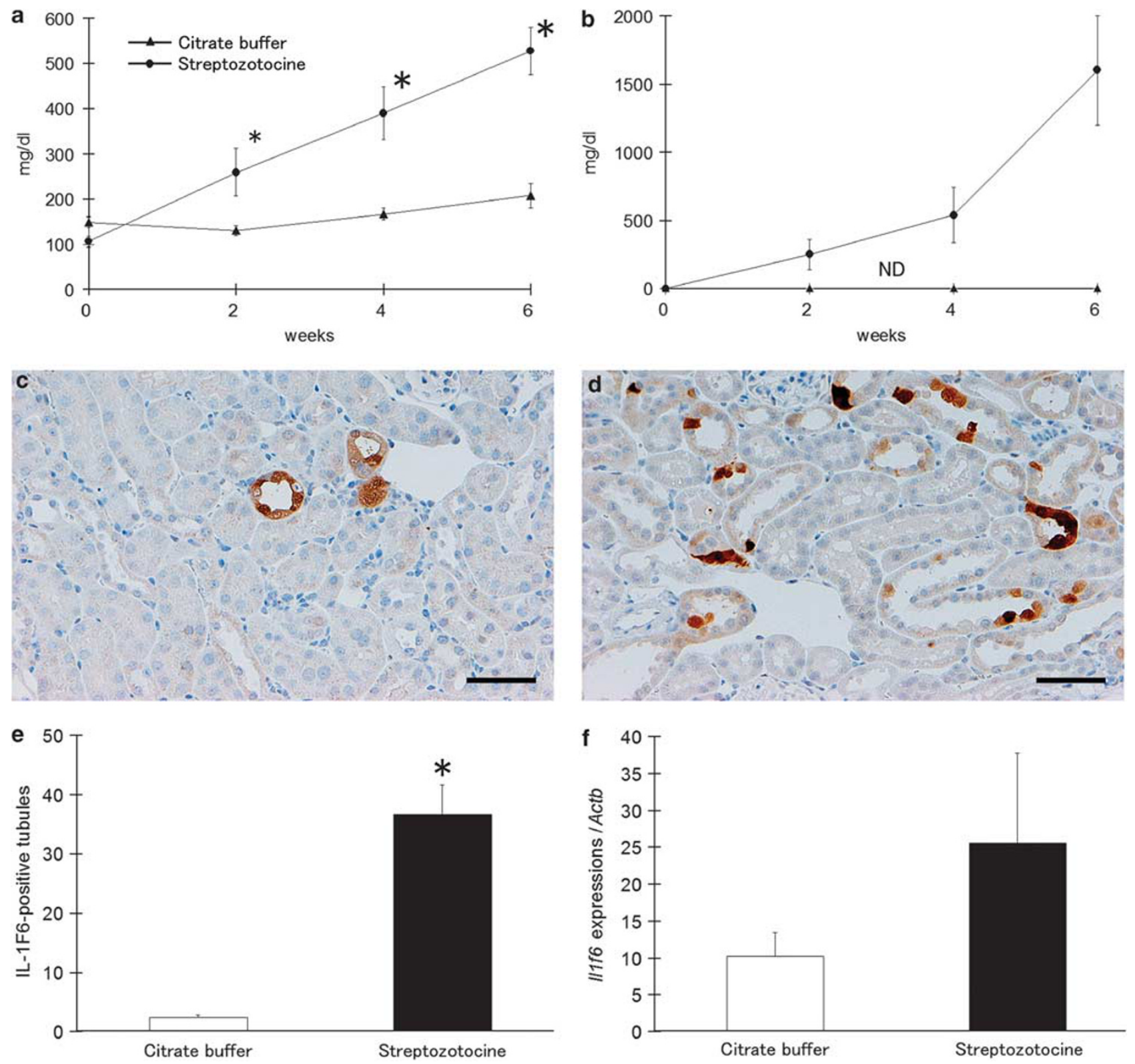

Figure 6 Blood glucose, urine glucose, and IL-1F6 protein levels, and II1f6 mRNA expressions in STZ-induced diabetic mice. (a, b) Time course of blood (a) and urine (b) glucose levels in the citrate buffer (CB) or STZ-administered group. Each value is expressed as mean (s.e.); ${ }^{*}$ : significantly different from mice in the $\mathrm{CB}$ group for each week (Mann-Whitney $U$-test, $P<0.05$ ); $n=4$. ND: In mice belonging to the CB group, urinary glucose was not detected. (c, $\mathbf{d}$ ) IHC staining for IL-1F6 in the kidneys of STZ-administered mice at 15 weeks of age. For mice with mild changes in the renal histopathology, a few renal tubular epithelia that transformed to squamous morphology showed an IL-1F6-positive reaction (c). For mice with numerous dilated renal tubules, the number of IL-1F6-positive tubules remarkably increased (d). Bar $=50 \mu \mathrm{m}$. (e, f) The number of IL-1F6-positive tubules (e) and the levels of II1f6 mRNA expression (f) in the kidneys of mice belonging to the CB or STZ-administered group. Each value is expressed as mean (s.e.); *: significantly different from mice belonging to the CB group for each graph (Mann-Whitney $U$-test, $P<0.05$ ); $n=4$.

showed acanthosis and increase in the number of macrophages and T-cells in these lesions; they also suggested that IL-1F6 controlled tissue injuries, promoting local inflammation. These findings strongly suggested that IL-1F6 in renal tubules was associated with local vicious cycles of tubulointerstitial inflammation.
Nestin- and $\alpha$-SMA-expressing cells were infiltrated around IL-1F6-positive tubules, and their numbers correlated well with TIL development. $\alpha$-SMA is a conventional marker for myofibroblasts, and nestin, which is an intermediate filament and a newly reported marker for mesenchymal cells and renal fibrosis, is associated with increase in TGF- $\beta$ 

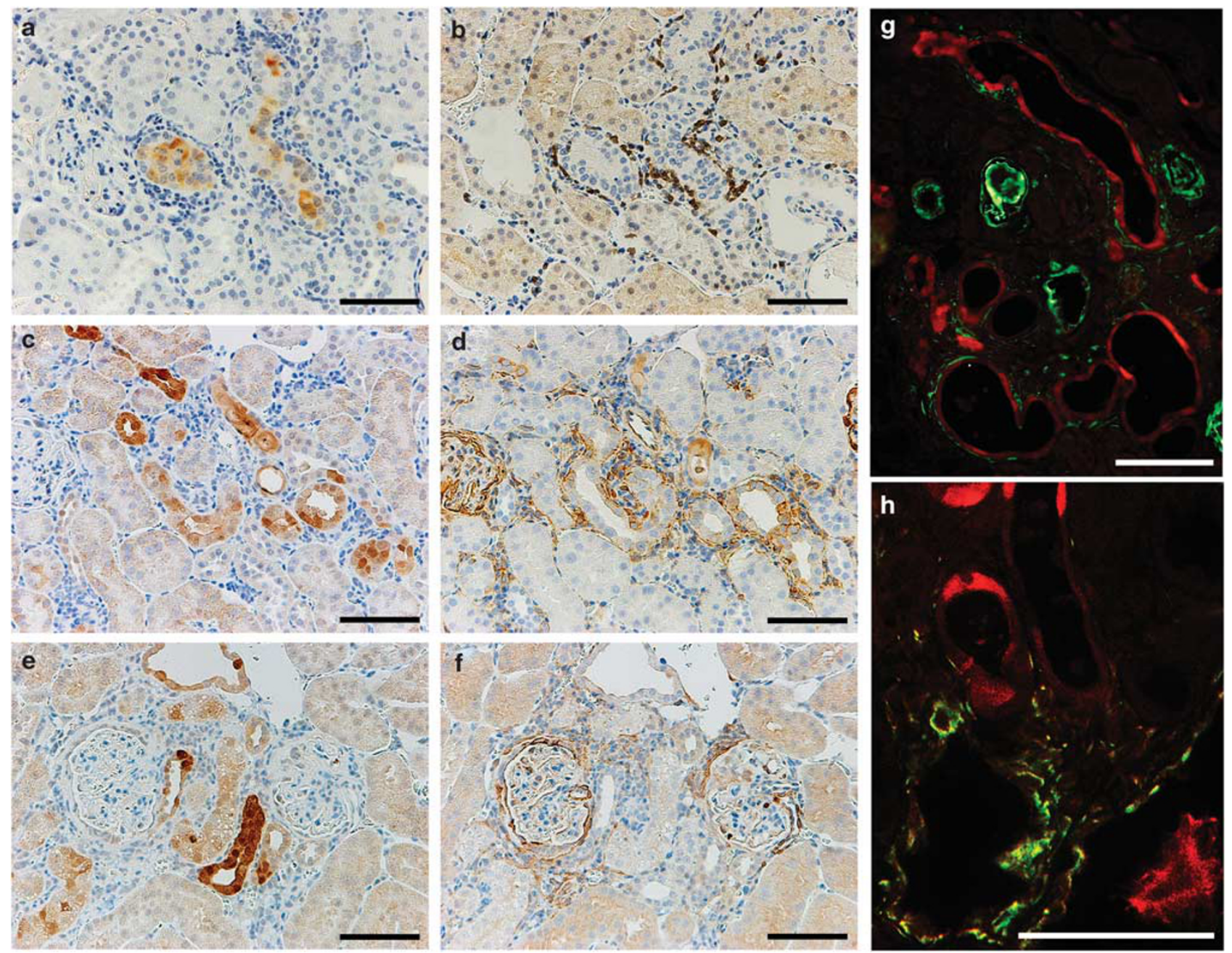

Figure 7 IL-1F6 and the other markers of TILs. (a, c, e) IHC staining for IL-1F6 in the kidney of a female MRL/lpr mouse at 4 months of age. Bar $=50 \mu$ m. (b) IHC staining for CD3 cells in serial section to panel a. CD3-positive cells infiltrated tissues around the IL-1F6-positive tubules. Bar $=50 \mu \mathrm{m}$. (d) IHC for nestin in serial section to panel c. Nestin-positive reactions were observed around the IL-1F6-positive tubules. Some nestin- and IL-1F6-positive cells colocalized in the same tubules. Glomerular podocytes were also positive for nestin. Bar $=50 \mu \mathrm{m}$. (f) IHC for $\alpha$-SMA in series section to panel e. $\alpha$-SMA-positive reactions were observed around the IL-1F6-positive tubules. Some arterioles and mesenchymal cells around renal corpuscles also showed $\alpha$-SMA-positive reactions. Bar $=50 \mu \mathrm{m}$. (g, h) Double immunofluorescence for the detection of IL-1F6 and nestin in the kidney of a female MRL/Ipr mouse at 4 months of age. The sections were analyzed by confocal microscopy. IL-1F6- and nestin-positive reactions were visualized using TRITC-conjugated secondary antibody (red) and FITC-conjugated secondary antibody (green), respectively. In panel $\mathbf{g}$, nestin-positive reactions were observed around the IL-1F6-positive tubules. In panel $\mathbf{h}$, a part of positive reactions for IL-1F6 and nestin were fused in the same cytoplasm (yellow). Bar $=50 \mu \mathrm{m}$.

expression in TILs. ${ }^{28}$ Recently, it was reported that injured distal tubular cells increased the expressions of both TGF- $\beta$ and its receptors, contributing to the pathogenesis of renal fibrosis. ${ }^{29}$ Furthermore, in DN and unilateral ureteral obstruction (UUO) rat models, dilation of renal tubules was initiated at the distal segments and these lesions progressed to TILs. ${ }^{30,31}$ Our findings were partially consistent with these reports, and strong IL-1F6 expression was observed in dilated tubular epithelium in renal disease models, including the STZ-induced diabetic model. We speculate that local tubular IL-1F6 production might reflect tubular damage caused not only by inflammation but also by physical changes such as elongation of tubular lumina or increase in osmotic pressure due to changes in urinary glucose concentration. Eventually, these affected regions would lead to TILs.

\section{IL-1F6 Participates in Luminal Epithelial Deciduation}

In epithelial cells, downregulation of epithelial markers and upregulation of mesenchymal markers are known as epithelial-to-mesenchymal transitions (EMTs), and these transitions are accompanied by transformation to the fibroblastoid morphology. ${ }^{32}$ In these processes, TGF- $\beta$ and its receptors play important roles, especially in the regulation of E-cadherin. ${ }^{33}$ In the present study, co-culture of M-1 epithelial cells with immune cells resulted in increased mRNA expression of mesenchymal markers Illf6, Il6, and Tgfbr, and decreased 
a
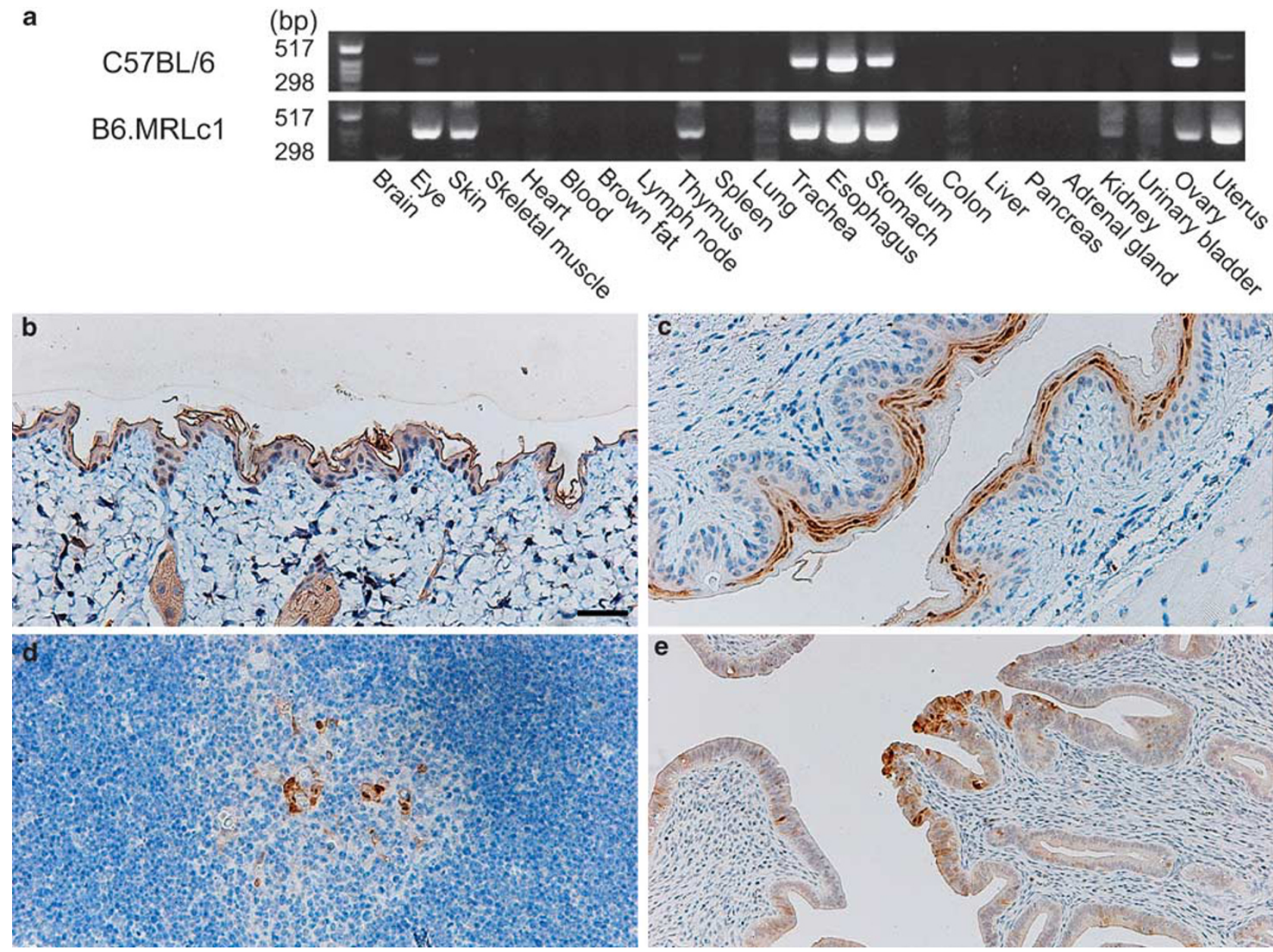

Figure 8 IL-1F6 protein and IIff6 mRNA expressions in whole organs of mice. (a) Real-time PCR analysis for I/1f6 mRNA expressions in the kidney of a 4-month-old female C57BL/6 mouse (upper lane) and B6.MRLc1 mouse (lower lane). Size markers are represented on the left. (b-e) IHC staining for IL-1F6 in the skin (b), esophagus (c), thymus (d), and uterus (e) of a 4-month-old female MRL/Ipr mouse. IL-1F6-positive reactions were observed in the epithelia, which showed squamous morphology (b-d) or the possibility of deciduous morphology (b-e). Bar $=20 \mu \mathrm{m}$.

expression of epithelial markers, thereby causing transformation to the squamous morphology. These renal EMTs subsequently contribute to the development of TILs. Iwano et $a l^{34}$ reported that EMTs are caused by injury to the PT epithelium, and that cells undergoing EMT eventually migrate to the tubulointerstitial space as transformed matrix-producing cells. Although no distal tubular EMT was reported, Ivanova $e t a l^{35}$ induced EMT in collecting ducts by TGF stimulations in vitro. However, in the present in vivo study, IL-1F6-positive cells were not observed in the renal interstitial space and their number tended to decrease in the tubular lumina. Furthermore, in our whole-organ analysis, IL-1F6 mRNA was mainly detected in organs with turnover of epithelial cells. Further, organs with IL-1F6-positive cells were prone to epithelial deciduation. Recently, EMT has been divided into stages according to changes in its related markers. ${ }^{36}$ From these findings, we surmised that injured DCT or CCD causes early-stage EMT leading to luminal epithelial deciduations (LEDs) and that IL-1F6 might participate in this process.

\section{Pathological Significance of IL-1F6 in Renal Disease}

We concluded that renal IL-1F6 overexpression was associated with (a) cellular infiltrations leading to TILs, (b) dilations of DCTs and CCDs, and (c) LEDs in these tubules. The pathological changes in the kidney of CGN mice were initiated by damage to glomeruli and proteinuria. ${ }^{13}$ However, IL-1F6 expression in M-1 cells was induced by inflammatory stimulations and not by the urinary protein. Furthermore, the pathological changes in the kidneys of the STZ-induced diabetic mice were initiated because of dilations of the DCT and CCD and not because of glomerular damage; ${ }^{15}$ further, an increased number of the IL-1F6-positive tubules were observed in this model, similar to that observed in the case of CGN and LN models. Therefore, in the LN and CGN models, inflammatory process associated with cellular infiltrations in 
a

C57BL/6

$\mathrm{MRL} / / p r$

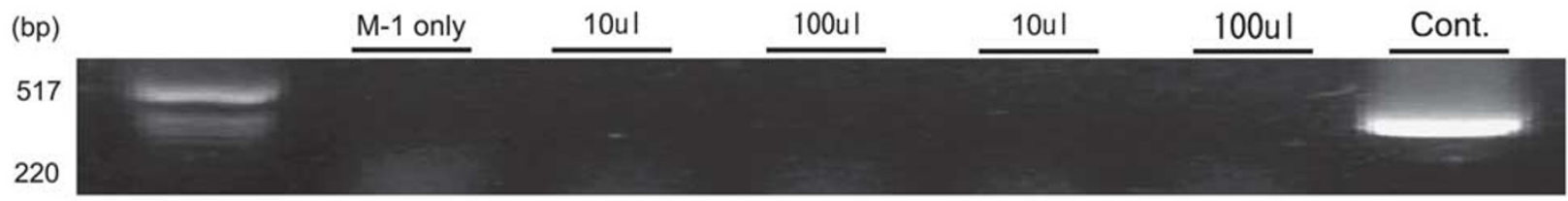

517

220

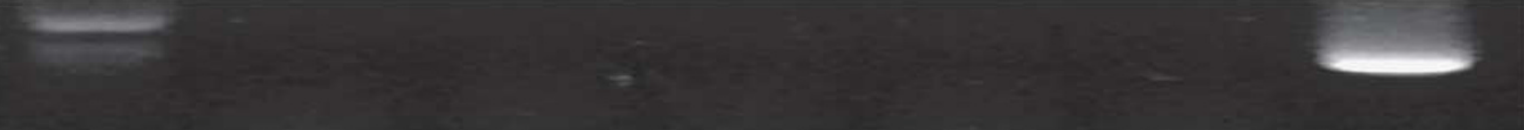
220
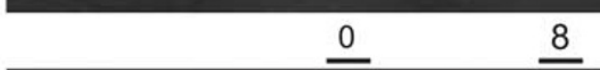

$\underline{16}$

$\underline{32}$

$\underline{64}$
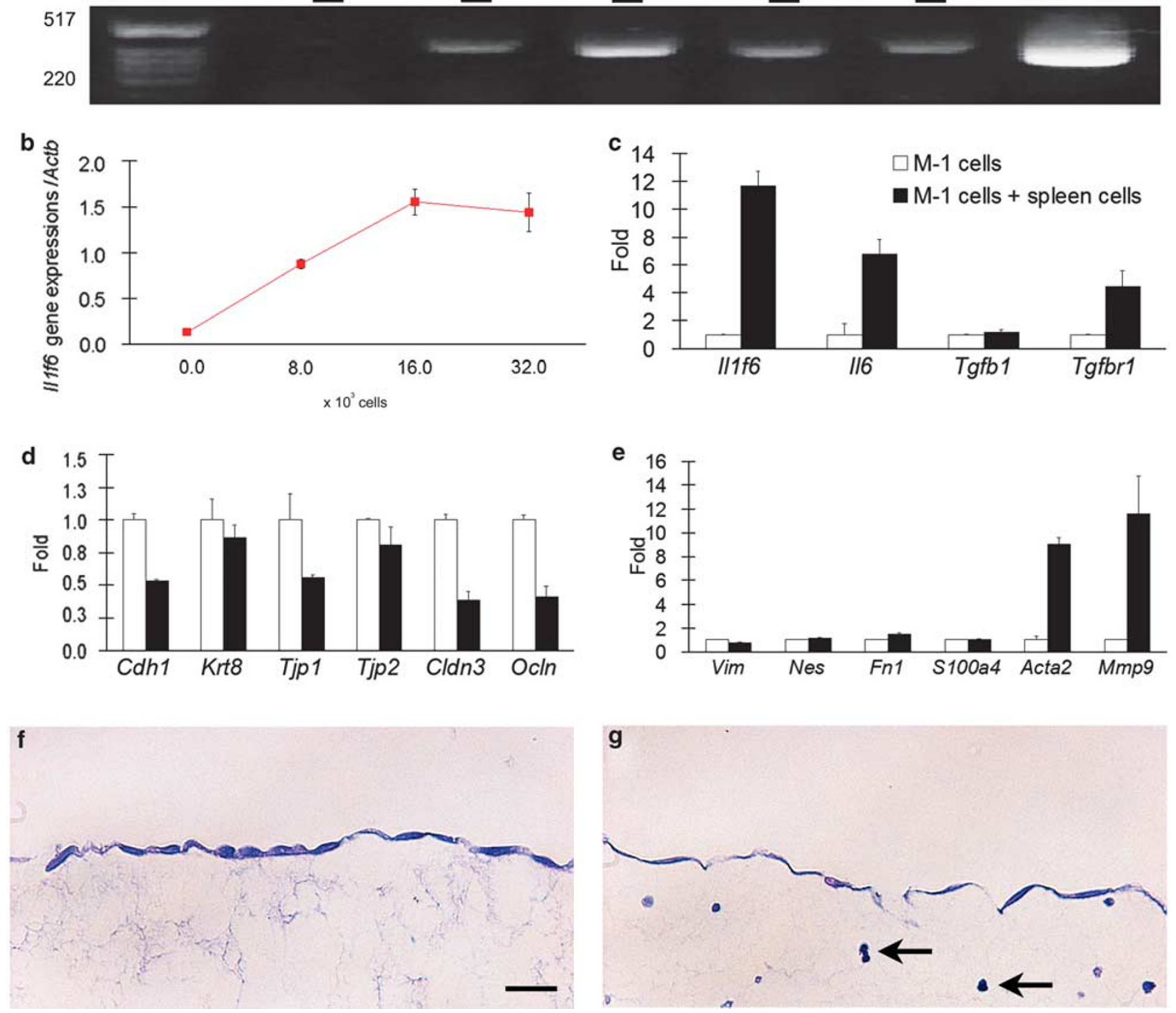

Figure 9 In vitro analysis of changes in the expression of various mRNAs and morphology with IIff6 inductions in M-1 cells. (a) Real-time PCR analysis for II1f6 mRNA expressions in M-1 cells derived from murine collecting ducts and stimulated with 10 or $100 \mu$ l of serum (upper lane) and urine (middle lane) of C57BL/6 and MRL/lpr mice or spleen cells (lower lane) of C57BL/6 mice. (b) Quantitative analysis of II1f6 mRNA expressions stimulated by spleen cells. Each value is expressed as mean (s.e.). (c-e) Quantitative analysis for mRNA expressions of II1f6, IL-6 (II6), TGF- $\beta$ (tgfb) family (c), and various epithelial (d) or mesenchymal (e) markers in M-1 cells stimulated by spleen cells. Each value is expressed as mean (s.e.) and represents the fold increase in the nonstimulated control. (f, g) Morphological changes in M-1 cells on collagen gel after stimulation with spleen cells (arrows). Non-stimulated M-1 cells show cuboidal to squamous epithelium and regular paving morphology (f). Stimulated M-1 cells transformed to squamous morphology, and cellular adhesions tended to loosen $(\mathbf{g})$. Bar $=20 \mu \mathrm{m}$. PAS stain. 

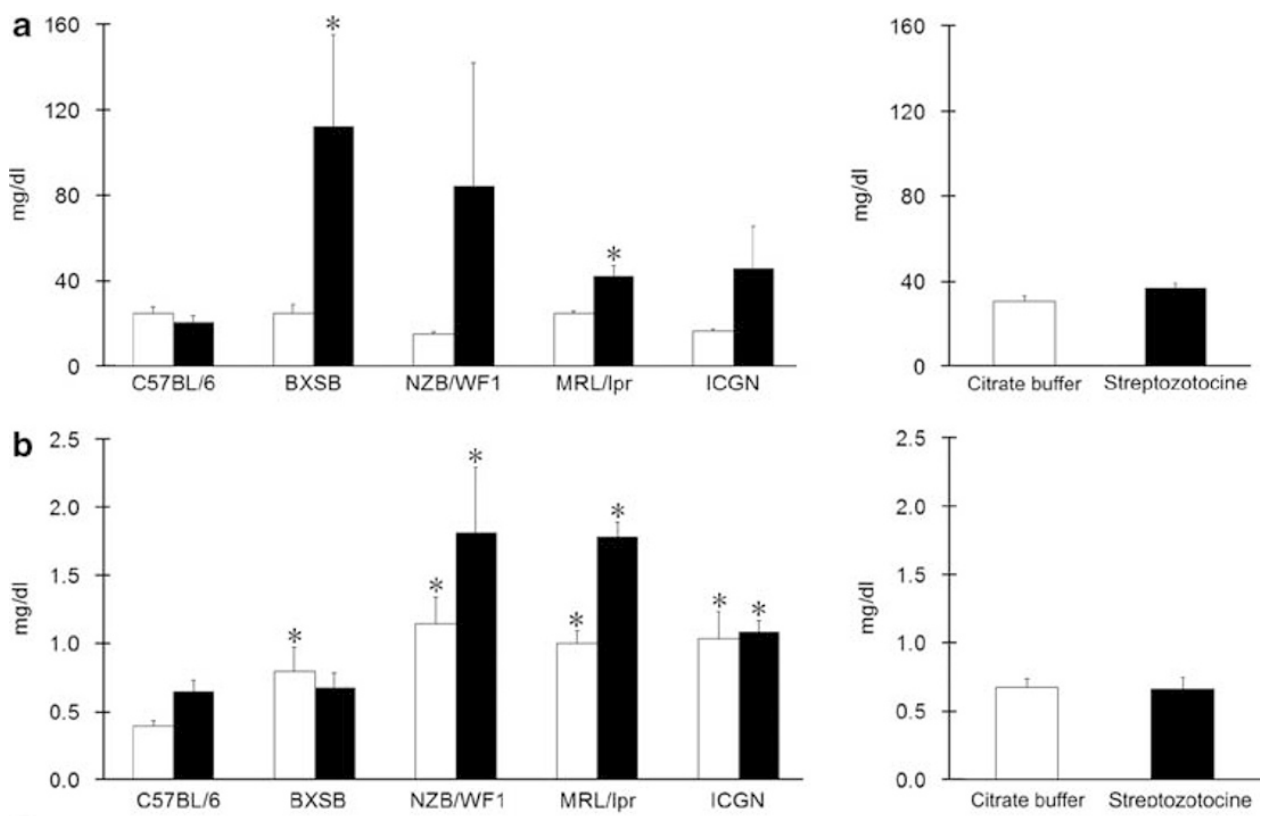

C
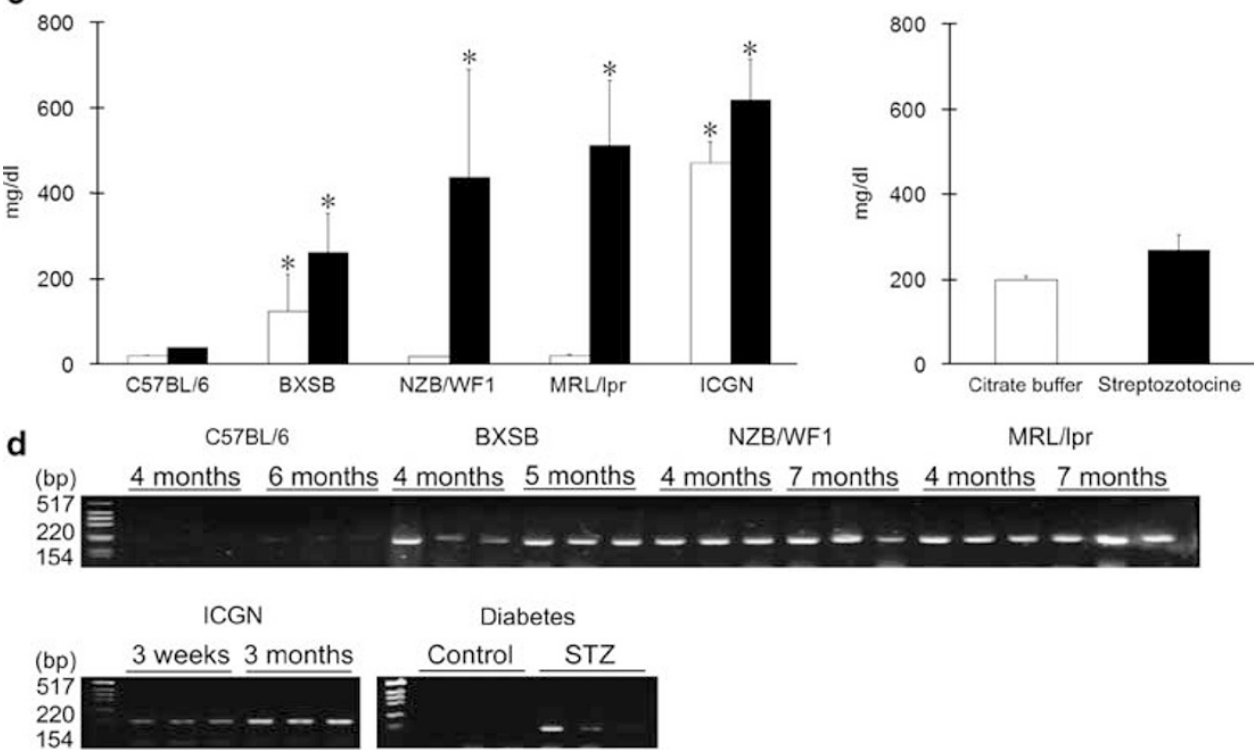

Figure 10 Clinical parameters and detection of urine II1f6 mRNA in various renal disease models. (a-c) Serum blood urea nitrogen (a), creatinine (b), and urine albumin (c) inC57BL/6, lupus (BXSB, NZB/WF1, MRL/lpr), and NS model (ICGN) mice in the early (left columns) and late stages of the disease (right columns), and CB or STZ-administered mice. Each value is expressed as mean (s.e.); ${ }^{*}$ : significantly different from C57BL/6 mice for each week or CB group in STZ-induced diabetic mice (Mann-Whitney U-test, $P<0.05$ ); $n=3$ (C57BL/6, lupus, NS models); $n=4$ (CB or STZ-administered mice). (d) Real-time PCR analysis of $\| 11 f 6$ mRNA from urine samples. Twenty microliters of urine from each animal were analyzed. Size markers are represented on the left.

tissues surrounding the renal corpuscles close to the DCTs and CCDs would induce IL-1F6. On the other hand, tubular IL-1F6 expression could also be induced by inflammation-independent process such as dilations of the lumen in QJ;diabetic models. The distal segment of renal tubules contain the macula densa, which is found in the juxtaglomerular apparatus; the juxtaglomerular apparatus regulates the renin-angiotensin and tubuloglomerular feedback systems, which are central to the maintenance of renal function. ${ }^{37,38}$ Therefore, we think that tubular damage is a critical condition that results in impair- ment of nephron function; moreover, the DCT, which is shorter than the PT, is more prone to tubular damage than the PT. Evaluation of tubular damage is essential for understanding renal pathology and prognosis in patients.

The present study suggested that IL-1F6 was transferred to the nucleus and/or excreted in the urine. Furthermore, IL-1F6 mRNA was detected in the urine of disease model mice. These results and those of our in vitro study suggest that IL-1F6 exhibits autocrine/paracrine function, and finally enters the nucleus to mediate cell-signaling pathways 
associated with epithelial morphological changes. Interestingly, IL-6, one of the cytokines mediated by IL-1F6, is associated with renal pathogenesis such as tubular regeneration and is excreted in the urine in the case of renal disease. ${ }^{39,40}$ In future studies, urinary IL-1F6 protein and/or mRNA as biomarker of renal injury should be evaluated about the detection sensitivity and disease specificity.

Supplementary Information accompanies the paper on the Laboratory Investigation website (http://www.laboratoryinvestigation.org)

\section{ACKNOWLEDGEMENT}

This work was supported by grants from Research Fellowships for Young Scientists by the Japan Society for the Promotion of Science (no. 19000862), Grant-in-Aid for Young Scientists (Start-Up, no. 21880002), the Ministry of Education, Culture, Sports, Science and Technology, Japan (no. 19380162), and the Kuribayashi Foundation (no. 21-1).

\section{DISCLOSURE/CONFLICT OF INTEREST}

The authors declare no conflict of interest.

1. Lysaght MJ. Maintenance dialysis population dynamics: current trends and long-term implications. J Am Soc Nephrol 2002;13:37-40.

2. Nakai S, Masakane I, Akiba T, et al. Overview of regular dialysis treatment in Japan as of 31 December. Ther Apher Dial 2008;12:428-456.

3. Bonventre JV. Kidney injury molecule-1 (KIM-1): a specific and sensitive biomarker of kidney injury. Scand J Clin Lab Invest Suppl 2008;241: 78-83.

4. Tesch GH. MCP-1/CCL2: a new diagnostic marker and therapeutic target for progressive renal injury in diabetic nephropathy. Am J Physiol Renal Physiol 2008;294:697-701.

5. Shui HA, Ka SM, Yang SM, et al. Osteopontin as an injury marker expressing in epithelial hyperplasia lesions helpful in prognosis of focal segmental glomerulosclerosis. Transl Res 2007;150:216-222.

6. Bylander J, Li Q, Ramesh G, et al. Targeted disruption of the meprin metalloproteinase beta gene protects against renal ischemiareperfusion injury in mice. Am J Physiol Renal Physiol 2008;294: 480-490.

7. Lee HJ, Wark AW, Corn RM. Microarray methods for protein biomarker detection. Analyst 2008;133:975-983.

8. Kim JH, Ha IS, Hwang $\mathrm{Cl}$, et al. Gene expression profiling of anti-GBM glomerulonephritis model: the role of NF-kappaB in immune complex kidney disease. Kidney Int 2004;66:1826-1837.

9. Teramoto K, Negoro N, Kitamoto K, et al. Microarray analysis of glomerular gene expression in murine lupus nephritis. J Pharmacol Sci 2008;106:56-67.

10. Nangaku M. Mechanisms of tubulointerstitial injury in the kidney: final common pathways to end-stage renal failure. Intern Med 2004;43:9-17.

11. Ichii O, Konno A, Sasaki N, et al. Autoimmune glomerulonephritis induced in congenic mouse strain carrying telomeric region of chromosome 1 derived from MRL/MpJ. Histol Histopathol 2008;23:411-422.

12. Ichii $\mathrm{O}$, Konno A, Sasaki $\mathrm{N}$, et al. Altered balance of inhibitory and active Fc gamma receptors in murine autoimmune glomerulonephritis. Kidney Int 2008;74:339-347.

13. Ichii O, Konno A, Sasaki N, et al. Onset of autoimmune glomerulonephritis derived from the telomeric region of MRL-chromosome 1 is associated with the male sex hormone in mice. Lupus 2009;18:491-500.

14. Gurley SB, Clare SE, Snow KP. Impact of genetic background on nephropathy in diabetic mice. Am J Physiol Renal Physiol 2006;290:214-222.

15. Tamura J, Konno A, Hashimoto $Y$, et al. Upregulation of renal renin-angiotensin system in mouse diabetic nephropathy. Jpn J Vet Res 2005;53:13-26.
16. Barksby HE, Lea SR, Preshaw PM, et al. The expanding family of interleukin-1 cytokines and their role in destructive inflammatory disorders. Clin Exp Immunol 2007;149:217-225.

17. Towne JE, Garka KE, Renshaw BR, et al. Interleukin (IL)-1F6, IL-1F8, and IL-1F9 signal through IL-1Rrp2 and IL-1RAcP to activate the pathway leading to NF-kappaB and MAPKs. J Biol Chem 2004:279:13677-13688.

18. Westacott Cl, Whicher JT, Barnes IC, et al. Synovial fluid concentration of five different cytokines in rheumatic diseases. Ann Rheum Dis 1990;49:676-681.

19. Kay J, Calabrese L. The role of interleukin-1 in the pathogenesis of rheumatoid arthritis. Rheumatology 2004;43:2-9.

20. Milner JM, Cawston TE. Matrix metalloproteinase knockout studies and the potential use of matrix metalloproteinase inhibitors in the rheumatic diseases. Curr Drug Targets Inflamm Allergy 2005;4: 363-375.

21. Graves DT, Cochran D. The contribution of interleukin-1 and tumor necrosis factor to periodontal tissue destruction. J Periodontol 2003;74:391-401.

22. Kornman KS, Page RC, Tonetti MS. The host response to the microbial challenge in periodontitis: assembling the players. Periodontol 2000 1997:14:33-53.

23. Magne D, Palmer G, Barton JL, et al. The new IL-1 family member IL-1F8 stimulates production of inflammatory mediators by synovial fibroblasts and articular chondrocytes. Arthritis Res Ther 2006;8:R80.

24. Eddy AA. Molecular insights into renal interstitial fibrosis. J Am Soc Nephrol 1996:7:2495-2508

25. Yoshioka K, Takemura T, Murakami K, et al. In situ expression of cytokines in IgA nephritis. Kidney Int 1993;44:825-833.

26. Nikolic-Paterson DJ, Main IW, Tesch GH, et al. Interleukin-1 in renal fibrosis. Kidney Int Supp 1996;54:S88-S90.

27. Blumberg $\mathrm{H}$, Dinh $\mathrm{H}$, Trueblood ES, et al. Opposing activities of two novel members of the IL-1 ligand family regulate skin inflammation. J Exp Med 2007;204:2603-2614.

28. Sakairi T, Hiromura K, Yamashita S, et al. Nestin expression in the kidney with an obstructed ureter. Kidney Int 2007;72: 307-318.

29. Liu HC, Liao TN, Lee TC, et al. Albumin induces cellular fibrosis by upregulating transforming growth factor-beta ligand and its receptors in renal distal tubule cells. J Cell Biochem 2006;97:956-968.

30. Obineche EN, Mensah-Brown E, Chandranath SI, et al. Morphological changes in the rat kidney following long-term diabetes. Arch Physiol Biochem 2001;109:241-245.

31. Kida Y, Sato T. Tubular changes in obstructed kidney of adult mice evaluated using immunohistochemistry for segment-specific marker. Histol Histopathol 2007;22:291-303.

32. Strutz FM. EMT and proteinuria as progression factors. Kidney Int 2008;75:475-481.

33. Peinado $\mathrm{H}$, Olmeda D, Cano A. Snail, Zeb and bHLH factors in tumour progression: an alliance against the epithelial phenotype? Nat Rev Cancer 2007;7:415-428.

34. Iwano M, Plieth D, Danoff TM, et al. Evidence that fibroblasts derive from epithelium during tissue fibrosis. J Clin Invest 2002;110:341-350.

35. Ivanova L, Butt MJ, Matsell DG. Mesenchymal transition in kidney collecting duct epithelial cells. Am J Physiol Renal Physiol 2008;294:1238-1248.

36. Grünert $\mathrm{S}$, Jechlinger $\mathrm{M}$, Beug $\mathrm{H}$. Diverse cellular and molecular mechanisms contribute to epithelial plasticity and metastasis. Nat Rev Mol Cell Biol 2003;4:657-665.

37. Ichii O, Yabuki A, Ojima T, et al. Immunohistochemical localization of renin, NO synthase-1, and cyclooxygenase-2 in rodent kidney. Histol Histopathol 2008;23:143-150.

38. Peti-Peterdi J. Confocal imaging and function of the juxtaglomerular apparatus. Curr Opin Nephrol Hypertens 2005;14:53-57.

39. Homsi E, Ribeiro-Alves MA, Lopes de Faria JB, et al. Interleukin-6 stimulates tubular regeneration in rats with glycerol-induced acute renal failure. Nephron 2002;92:192-199.

40. Sheu JN, Chen MC, Chen SM, et al. Relationship between serum and urine interleukin- 6 elevations and renal scarring in children with acute pyelonephritis. Scand J Urol Nephrol 2009;43:133-137. 